\title{
Review
}

\section{Putative Survival Advantages in Young Apolipoprotein $\varepsilon 4$ Carriers are Associated with Increased Neural Stress}

\author{
Carr J. Smith ${ }^{\mathrm{a}, *}$, J. Wesson Ashford ${ }^{\mathrm{b}}$ and Thomas A. Perfetti ${ }^{\mathrm{c}}$ \\ ${ }^{a}$ Florida State University, Department of Nurse Anesthesia, Panama City, FL, USA \\ ${ }^{\mathrm{b}}$ Stanford University and VA Palo Alto Health Care System, Palo Alto, CA, USA \\ ${ }^{\mathrm{c}}$ Perfetti \& Perfetti LLC, Winston-Salem, NC, USA
}

Accepted 28 January 2018

\begin{abstract}
Inheritance of a single copy of the apolipoprotein E (APOE) $\varepsilon 4$ allele increases risk of Alzheimer's disease (AD) by 3-4-fold, with homozygosity associated with a $12-16$-fold increase in risk, relative to $\varepsilon 3$ allele homozygosity. There is a decreased risk associated with the APOE $\varepsilon 2$ allele. The pathological consequence of APOE genotype has led to intense efforts to understand the mechanistic basis of the interplay between APOE status and loss of synapses. Numerous $\varepsilon 4$ allele-related associations have been reported with the potential relevance of these associations to the pathogenesis of AD unknown at this time. In primarily young subjects, we have reviewed a representative body of literature on $\varepsilon 4$ allele-associations related to the following: cardiovascular responses; impacts on reproduction and fetal development; co-morbidities; resistance to infectious disease; responses to head injury; biochemical differences possibly related to neural stress; and brain structure-function differences. In addition, the literature on the association between the $\varepsilon 4$ allele and cognitive performance has been reviewed comprehensively. The weight-of-the-evidence supports the hypothesis that possession of the ancestral $\varepsilon 4$ allele in youth is associated with improved fitness during fetal development, infancy, and youth relative to the more recently appearing $\varepsilon 3$ allele, at the expense of decreased fitness in old age, which is substantially improved by the $\varepsilon 3$ allele. However, possession of the $\varepsilon 4$ allele is also associated with higher levels of synaptic macromolecular turnover, which likely stresses basic cellular neuroplasticity mechanisms. Clinical trials of potential AD therapeutics should consider APOE status as an enrollment criterion.
\end{abstract}

Keywords: Alzheimer's disease, apolipoprotein E, $\varepsilon 4$ allele, improved performance, youth

\section{INTRODUCTION}

Alzheimer's disease (AD) is a pathological condition adversely affecting the brain. AD has a large genetic component. The neuropathology is characterized by the presence of neurofibrillary tangles (NFTs) and neuritic plaques $[1,2]$. The modern

\footnotetext{
*Correspondence to: Carr J. Smith, PhD, DABT, Florida State University, Department of Nurse Anesthesia, 4750 Collegiate Drive, Panama City, FL 32405, USA. E-mail: csmith@pc.fsu.edu.
}

conceptualization of AD pathology dates from 1968 when Blessed et al. showed in elderly individuals that the NFTs correlated with the severity of the dementia, though the neuritic plaques, which contain cerebral amyloid- $\beta$ (A $\beta)$, did not [2]. A major advance in understanding $\mathrm{AD}$ pathology was the demonstration that $\mathrm{AD}$ pathology predominantly affects the posterior-temporal, inferior parietal, posterior cingulate, and medial temporal region [3], with a characteristic pattern of progression beginning in the entorhinal cortex involving neurofibrillary (NF) 
and microtubule associated protein-tau pathology rather than senile plaque and cerebral $A \beta$ pathology [4], consistent with the earlier findings of Blessed et al. [2].

Dementia is a condition involving impairment of cognitive function, which has deteriorated from a prior higher level, and causes social impairment. There are a few types of dementia, mostly frontotemporal (rare) and temporal-parietal (common). Patients with temporal-parietal dementia subdivide into approximately one third with pure $\mathrm{AD}$, one third not $\mathrm{AD}$, and one third being mixed, with the prevalence of mixed cases increasing with age. This progression of $\mathrm{AD}(\mathrm{NF} / \mathrm{NFT} /$ tau pathology) is clearly reflected by both altered cerebral blood flow [5] and cerebral metabolism [6, 7], as well as by PET tracers targeting tau $[8,9]$, with characteristic regional and stage-specific variations [9]. These changes in the brain are closely related to the impairments of memory function that are so typical of the dementia associated with $\mathrm{AD}$ and its progression $[10,11]$. This pattern has strongly suggested that AD pathology selectively attacks those neuroplastic brain systems which perform the functions of episodic memory $[12,13]$. The neuritic plaques and $A \beta$ are consistent components of AD pathology [14], which is the predominant cause of dementia. However, the distribution pattern of $A \beta$ pathology, which is found at least as early and diffusely in the neocortex as the tau pathology, is found first in most regions of the neocortex [15] but is generally not or much less related to cognitive changes than the tau pathology [16-18]. With a slowly progressing condition, mild cognitive impairment is a transition from normal cognition that precedes dementia, and is very poorly described [19].

Previously, we hypothesized that apolipoprotein E (APOE) $\varepsilon 4$ allele-associated AD risk is consistent with increased lifetime exposure to a neurotoxic process [20]. Specifically, if the hippocampal neurons of two individuals possess the same susceptibility to an endogenous or exogenous stress factor, the neurons with the highest turnover of proteins, lipids, and other macromolecules might experience a larger integrated dose of detriment. Small differences in pharmacokinetic effects might be amplified by the extremely long pre-symptomatic phase of $\mathrm{AD}$, i.e., average age of presentation for a homozygous $\varepsilon 4$ is about 68 years of age [20]. Studies conducted across the age spectrum from infancy through senescence have suggested that APOE $\varepsilon$ 4-positive status is associated with increased brain activity and macromolecule turnover in young healthy individuals, with the reverse extant in elderly subjects. In the current study, we extend our analysis from the limited number of studies examined in Smith and Ashford [20] and attempt herein to comprehensively examine the literature on reported associations between clinical conditions, cognitive performance, and presence or absence of the $\varepsilon 4$ allele in otherwise healthy young subjects.

The literature on associations between $\varepsilon 4$ status in otherwise healthy young subjects falls into several categories including: cardiovascular responses (Table 1); reproduction and development (Table 2); co-morbidities (Table 3); resistance to infectious disease (Table 4); responses to head injury (Table 5); biochemical differences possibly related to neural stress (Table 6); brain structure-function (Table 7); and mental performance (Table 8). Possession of the $\varepsilon 4$ allele is a strong risk factor for development of $\mathrm{AD}$ in the elderly, and all individuals possessing the $\varepsilon 4$ allele are increasingly likely to develop AD the older they live, relative to those without this allele. An understanding of the clinical conditions and cognitive performance characteristics idiosyncratic to healthy young persons who possess the $\varepsilon 4$ allele might assist in the complex task of disentangling the relative contributions of genetics and lifestyle that appear to play a role in how and when a given individual develops $\mathrm{AD}[21]$.

The mechanism through which inheritance of an allele of a protein associated with cholesterol metabolism, i.e., $\varepsilon 4$, exerts an increased risk for the development of AD later in life is not understood. One current hypothesis emphasizes that vulnerability to $\mathrm{AD}$ is based on the very high rate of formation and removal of synapses in the brain. In healthy individuals, the number of synapses formed and actively removed is estimated to be one trillion per day, presumably associated with constant learning and establishment of new memories. The amyloid-beta protein precursor (A $\beta P P)$ plays a central role in this aspect of neuroplasticity [13]. A considerable amount of evidence has related $A \beta P P$ to $A D$ [22], including a relationship between its $A \beta$ product and APOE genotype [23]. A $\beta P P$ can be cleaved either by the $\alpha$-secretase, which leads to increased local synapse production and prevents formation of the synaptotoxic $A \beta$ molecule or by the $\beta$-secretase, followed by $\gamma$-secretase, which leads to the removal of the affected synapse [22]. The control of the delicate balance between synapse creation and destruction is critical for learning and involves numerous mechanisms, with a positive neuronal action culminating in activation of the $\alpha$-secretase, while activation failure leads 


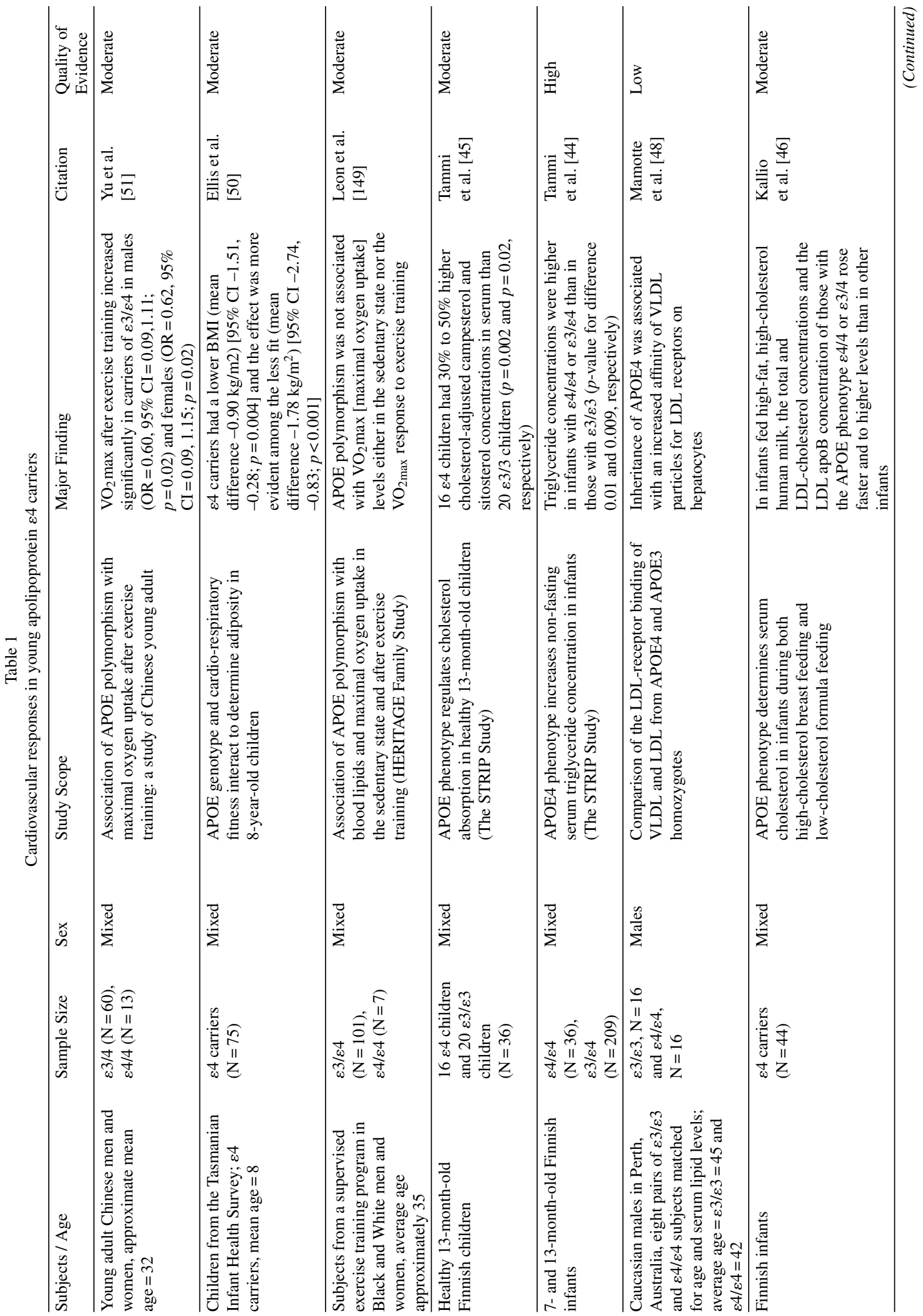




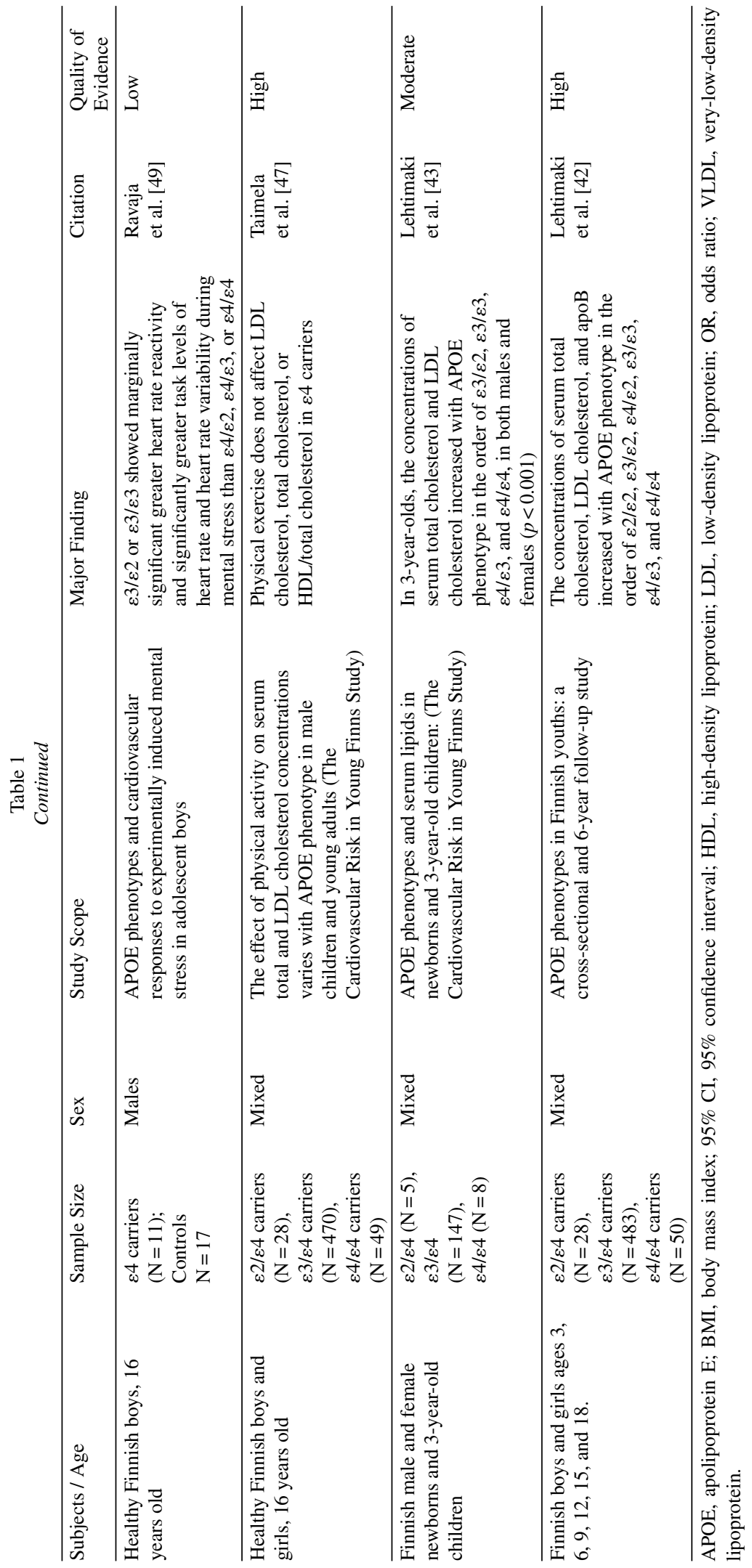




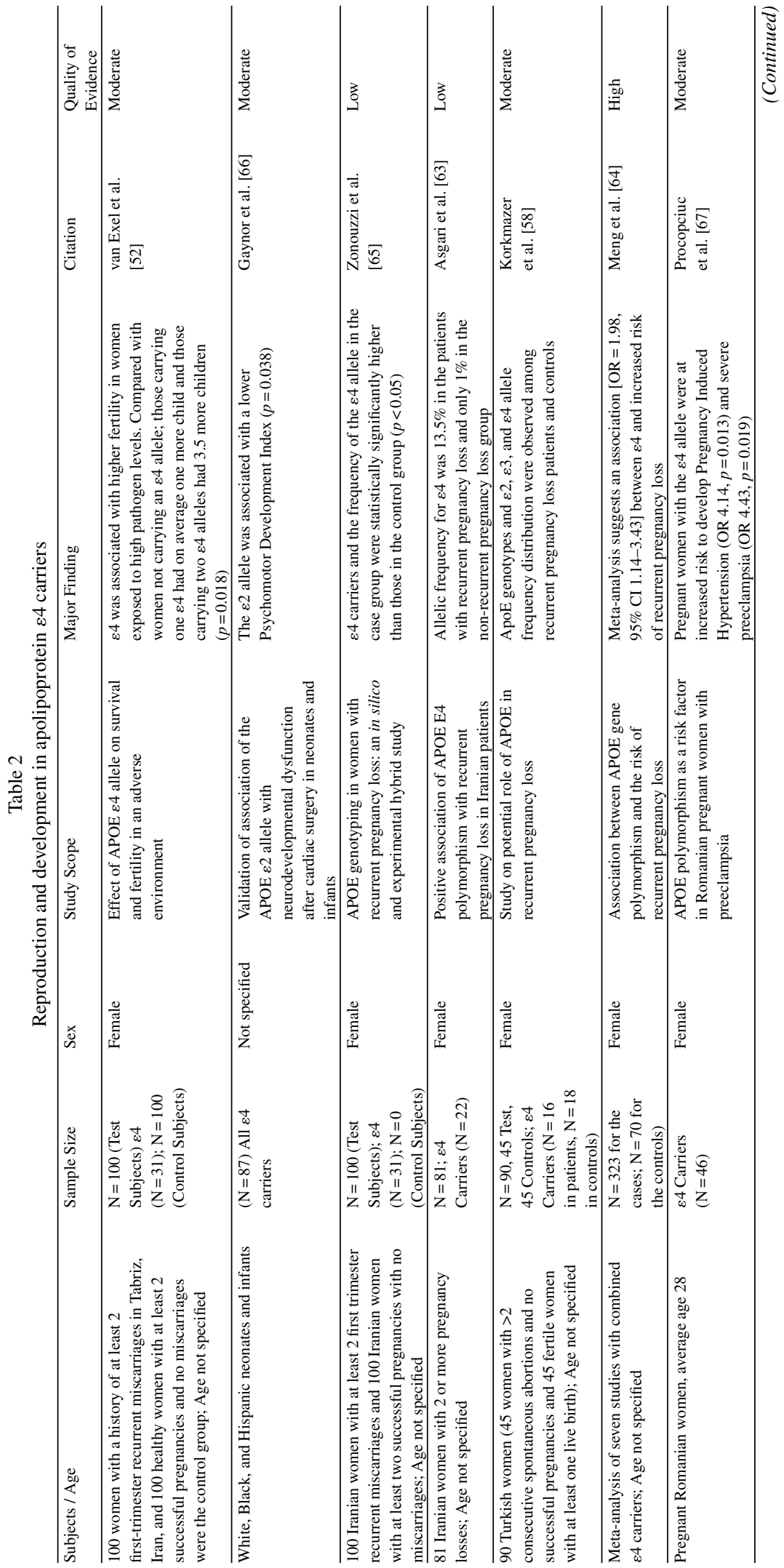



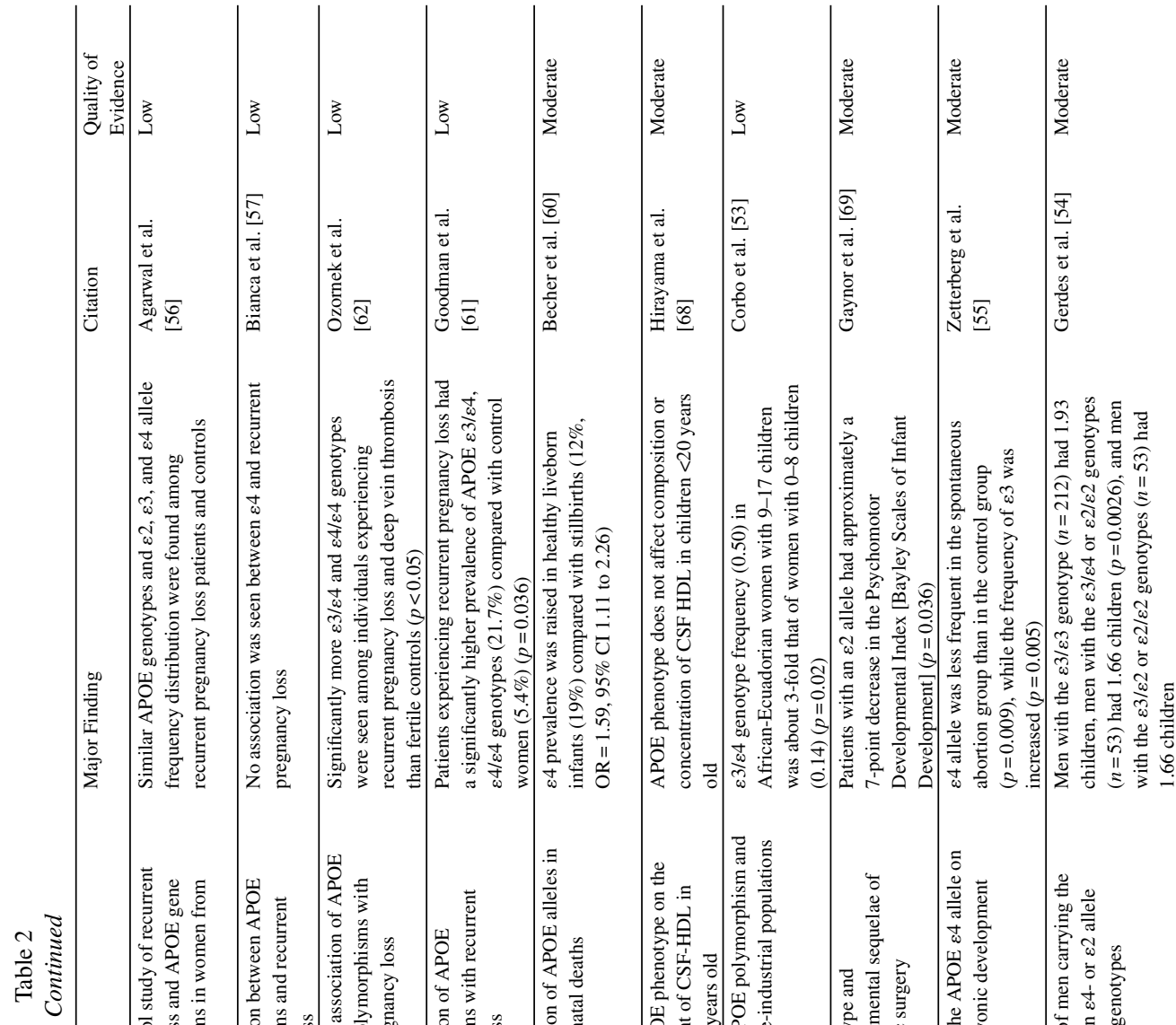

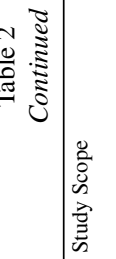
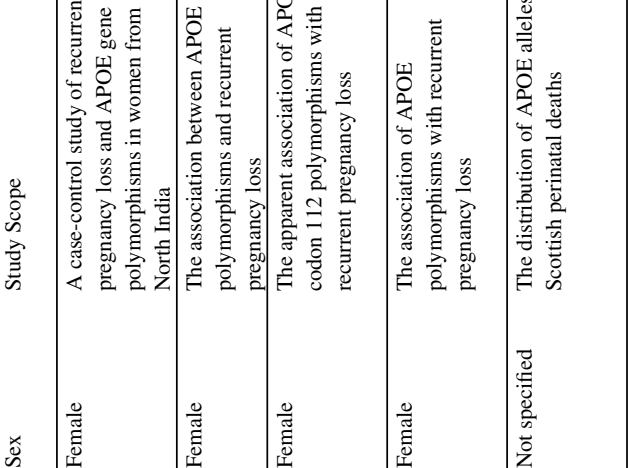

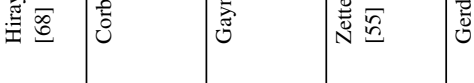

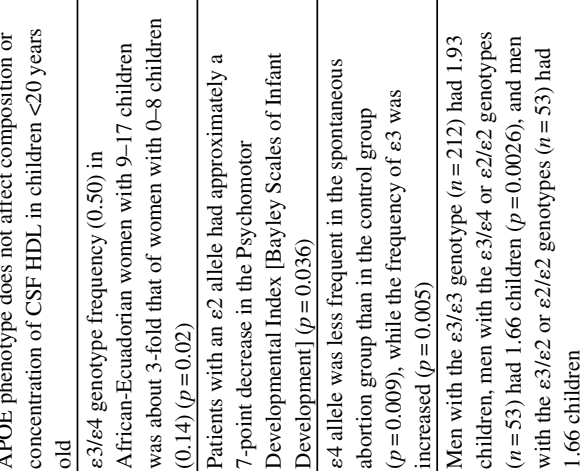

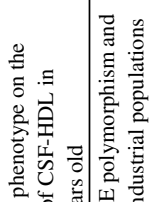

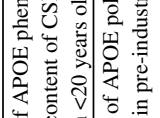

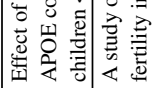

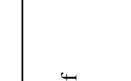




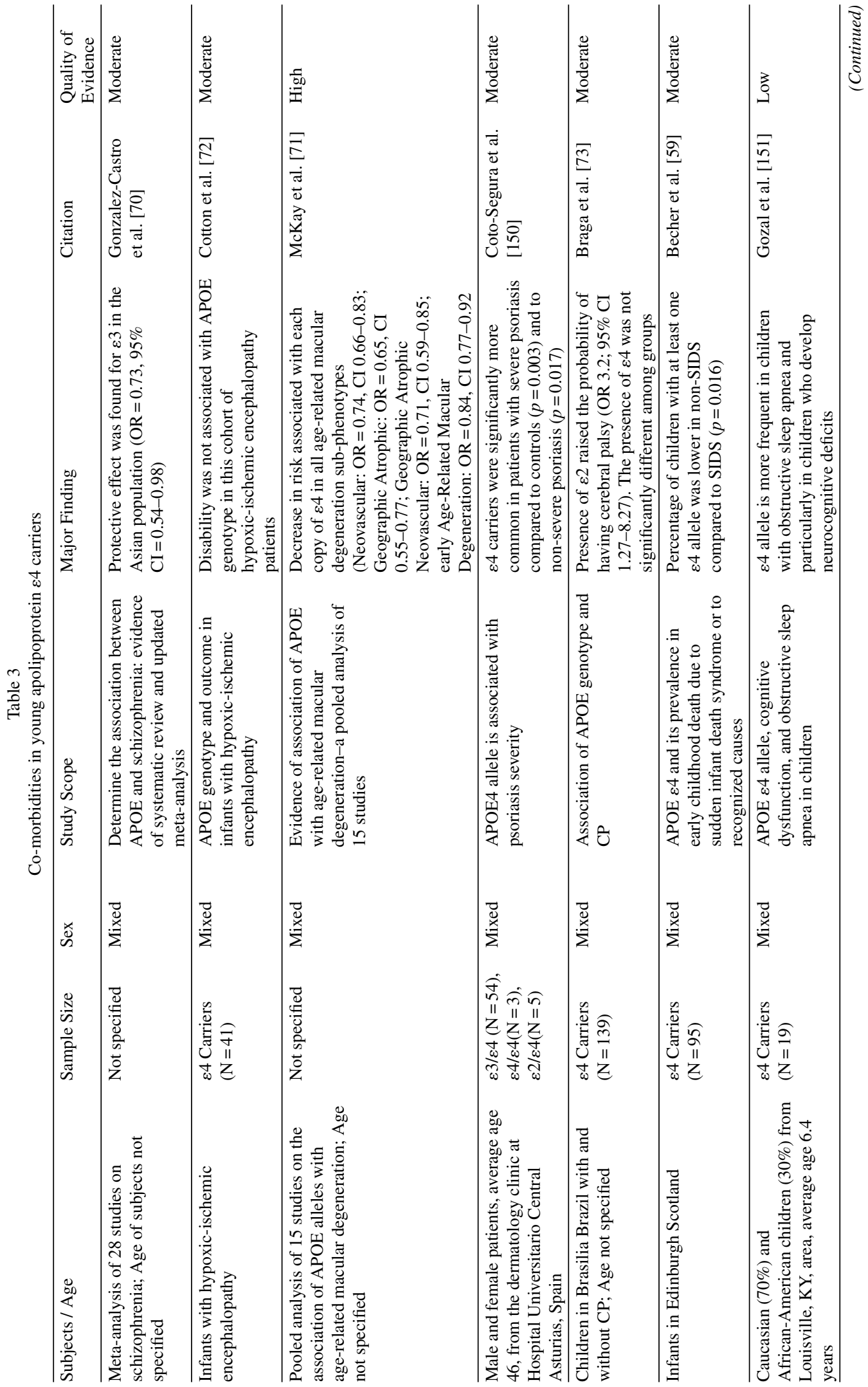




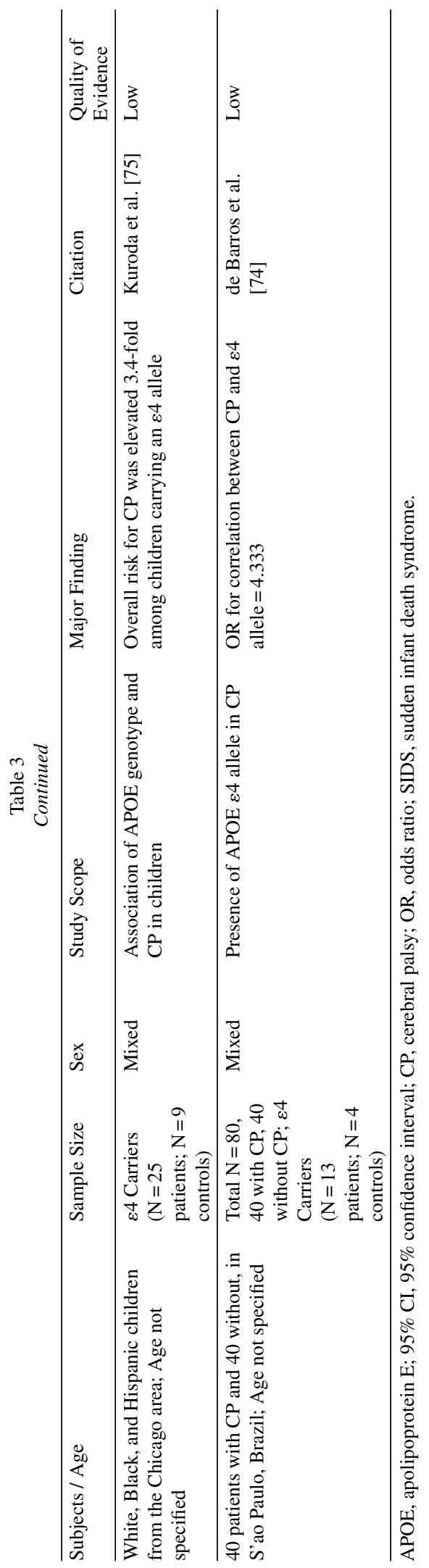




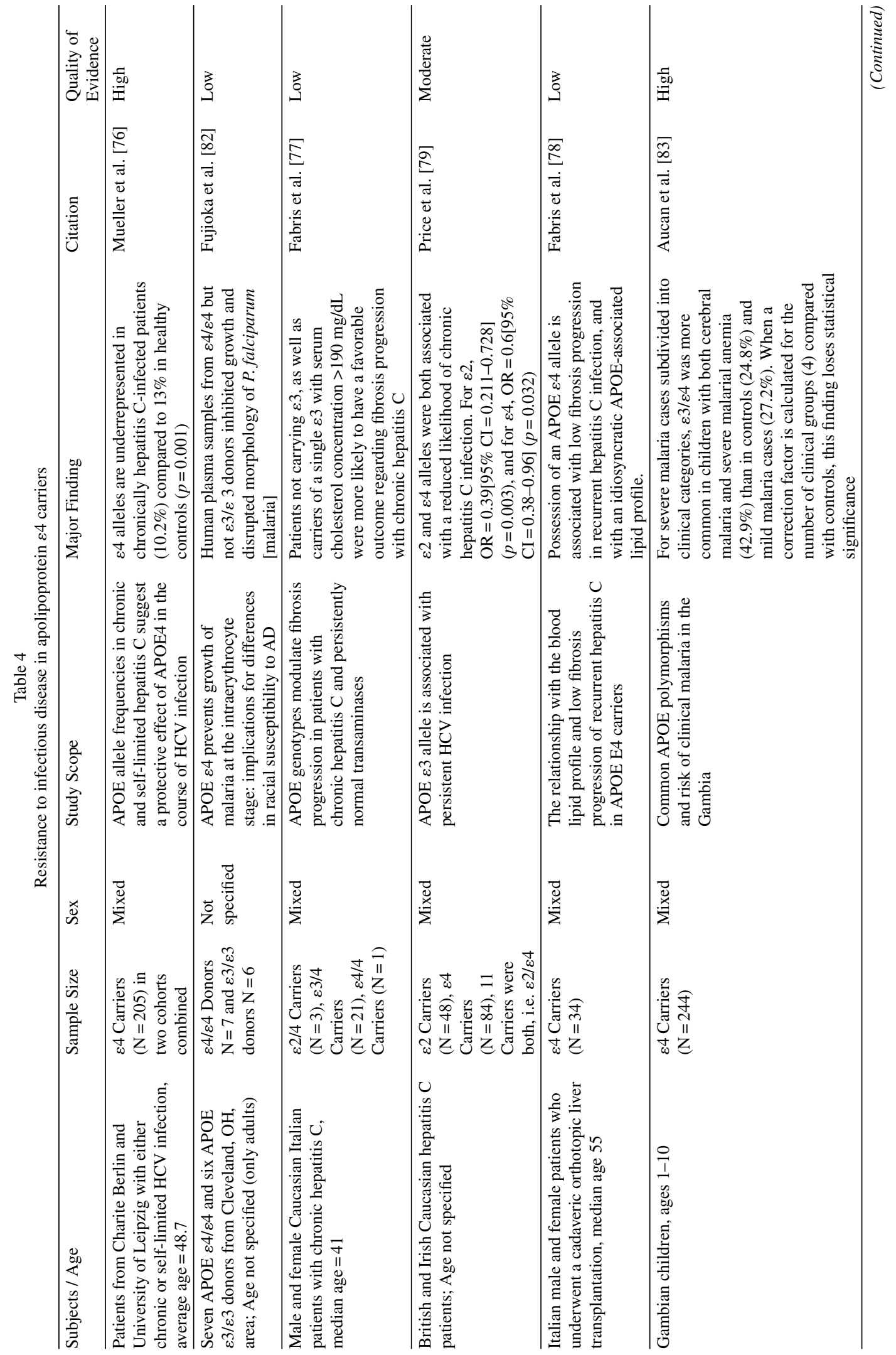




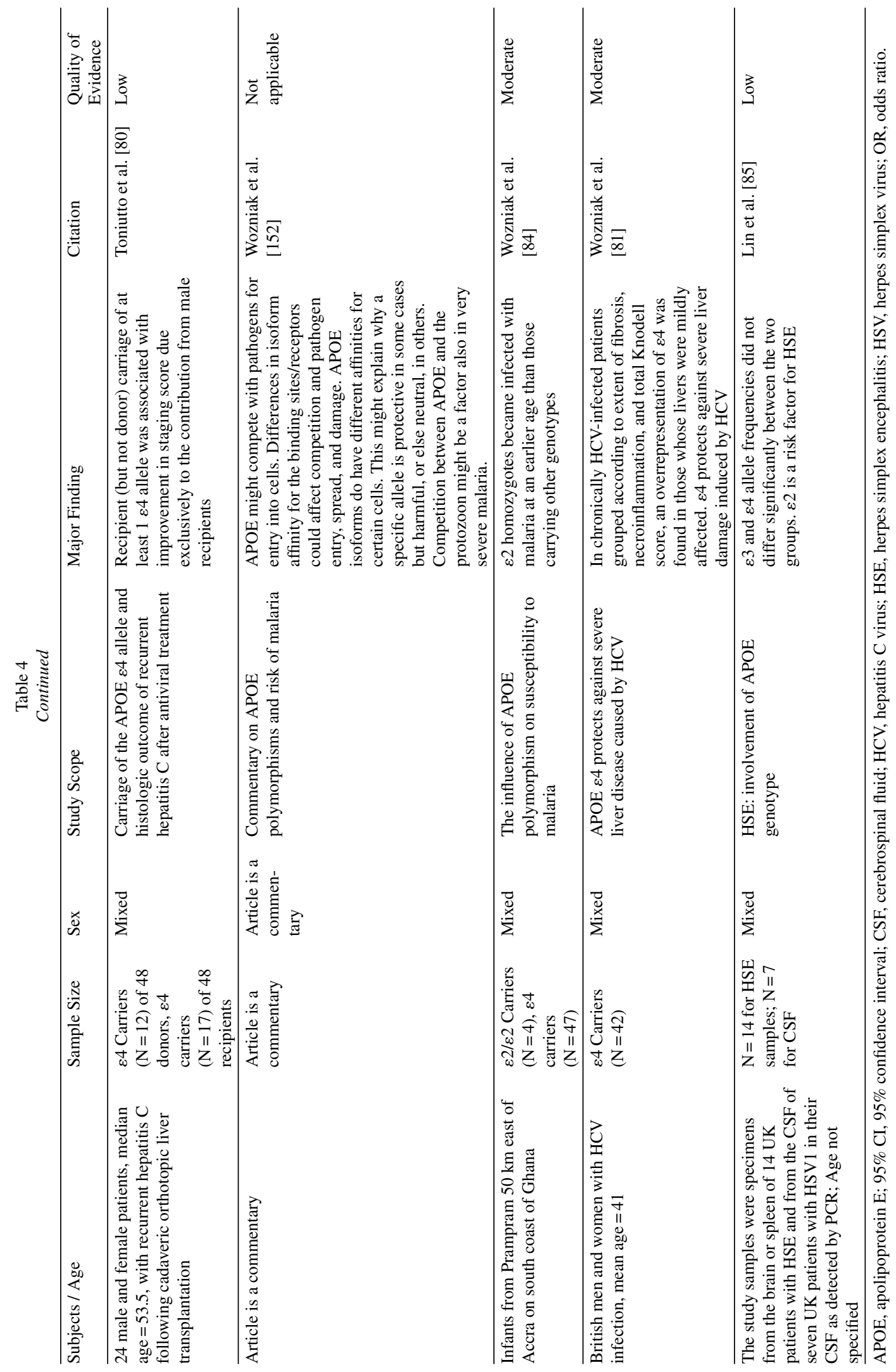




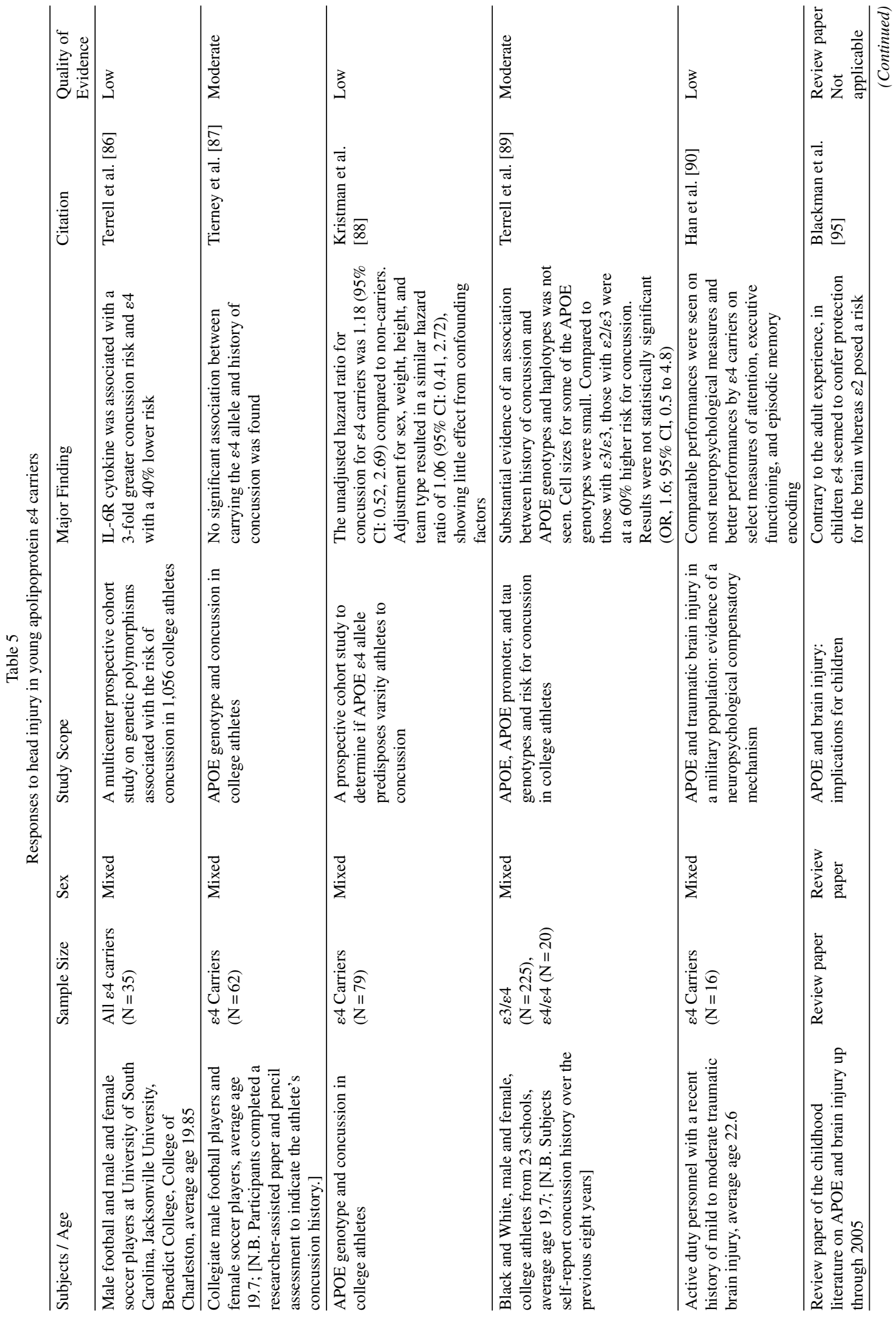




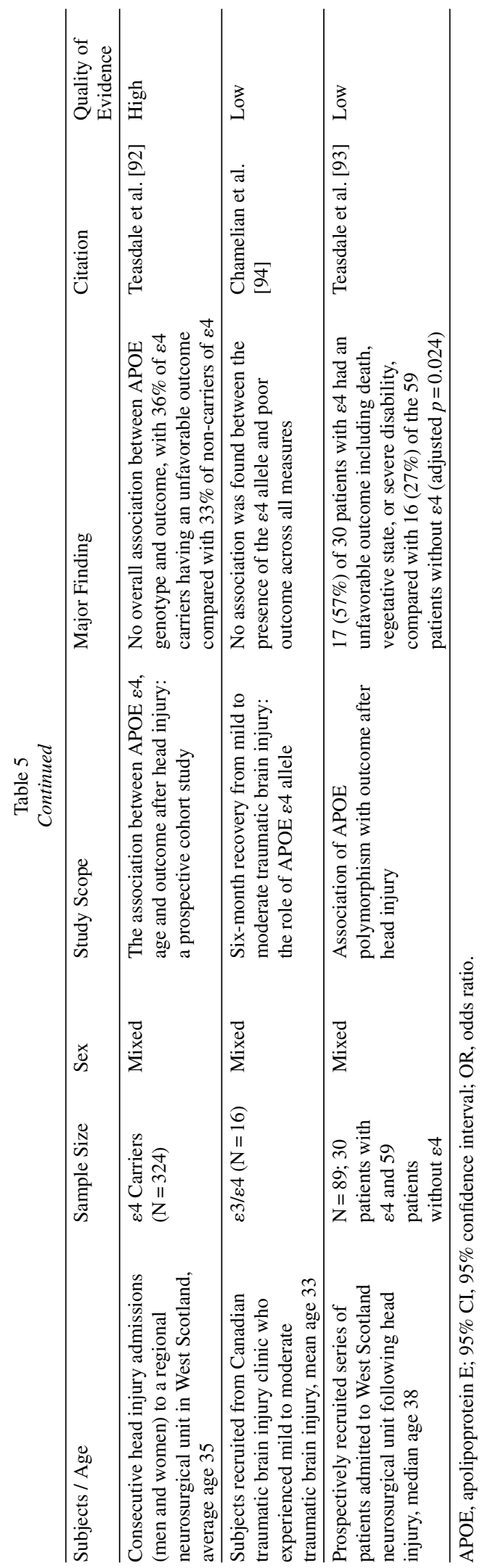




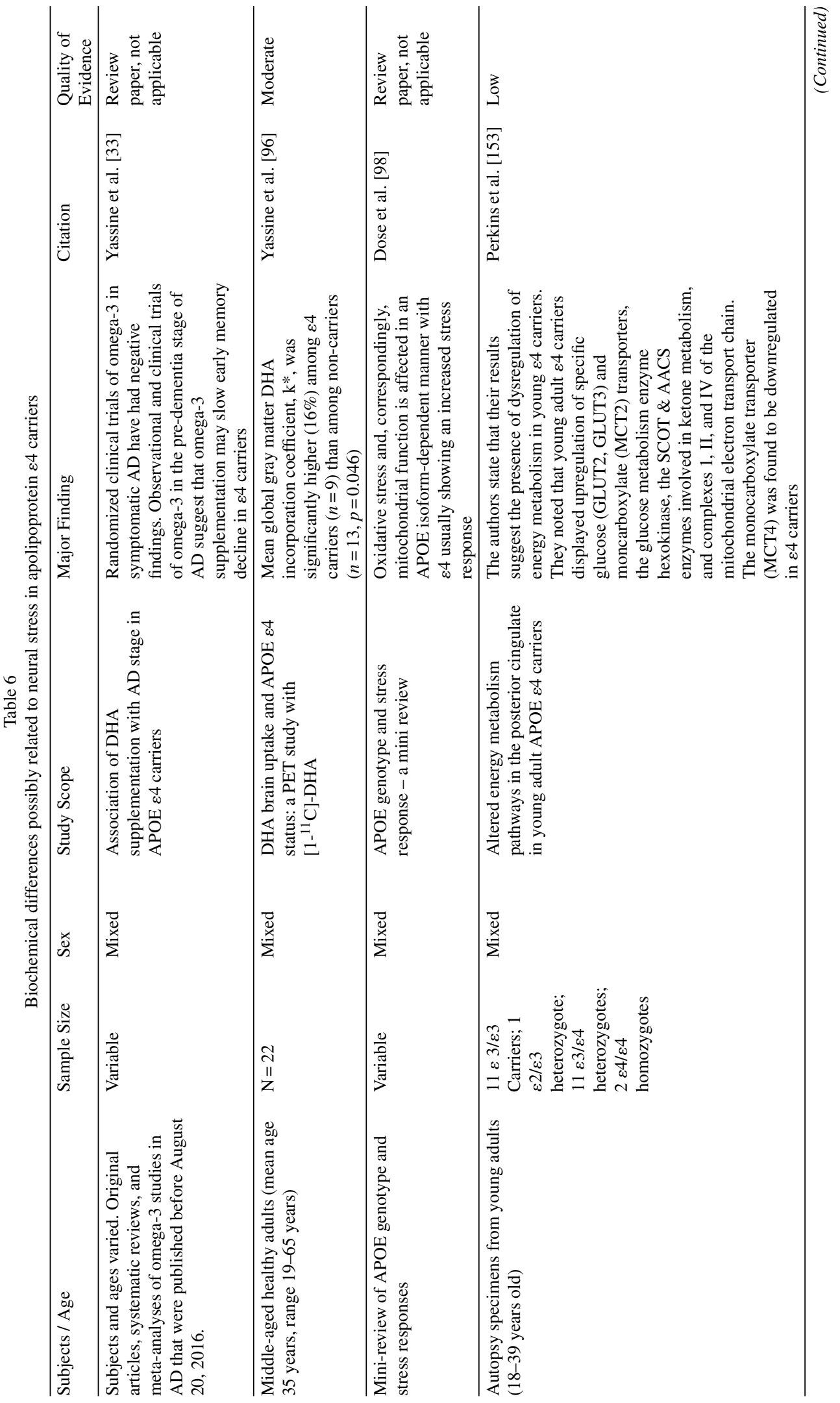




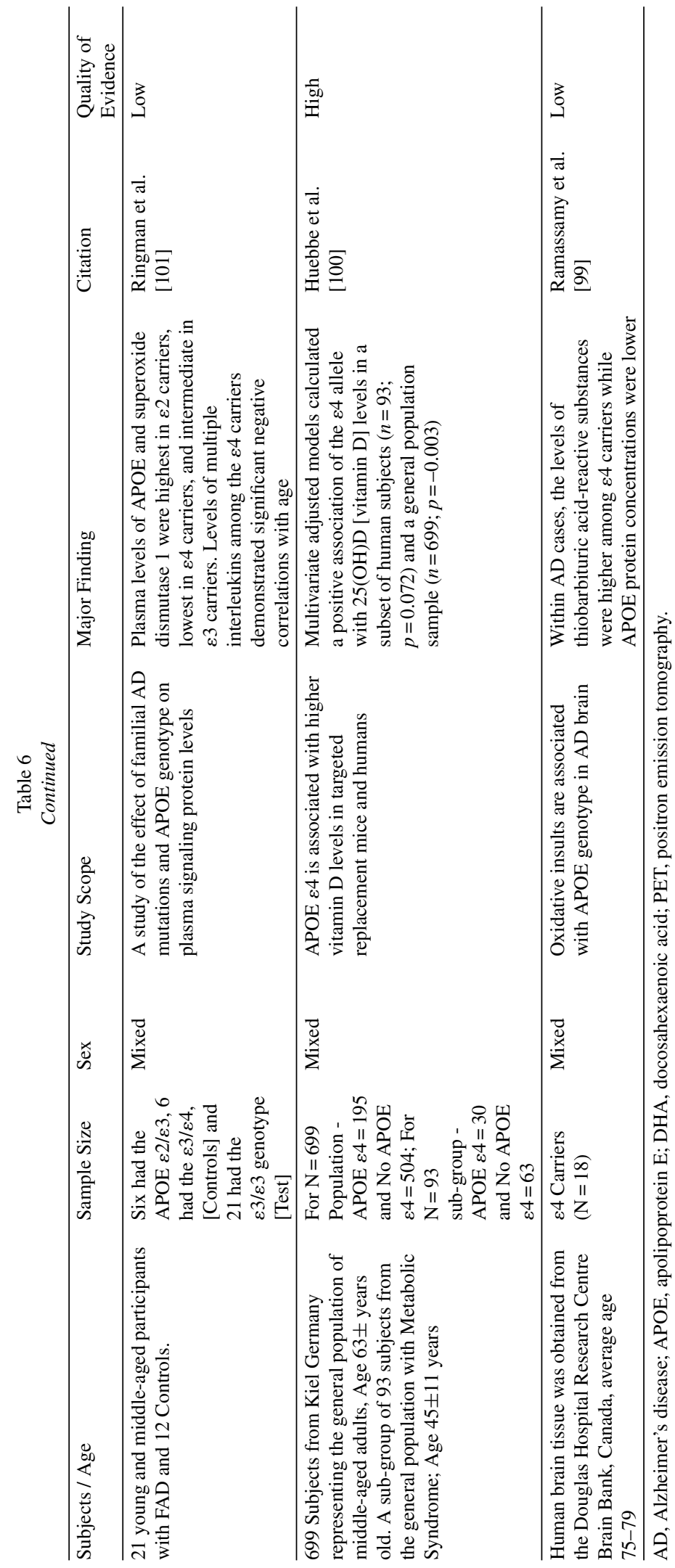




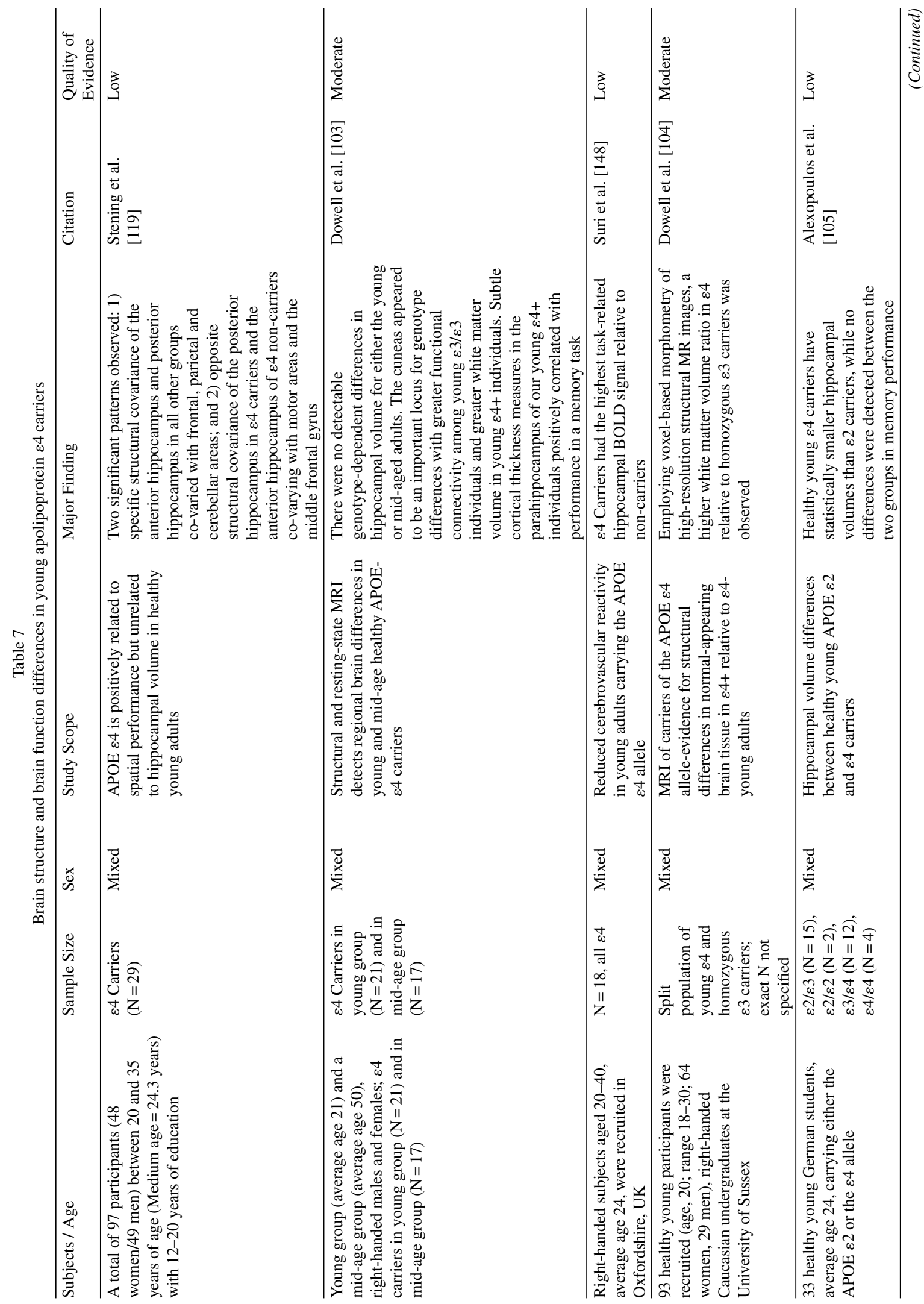




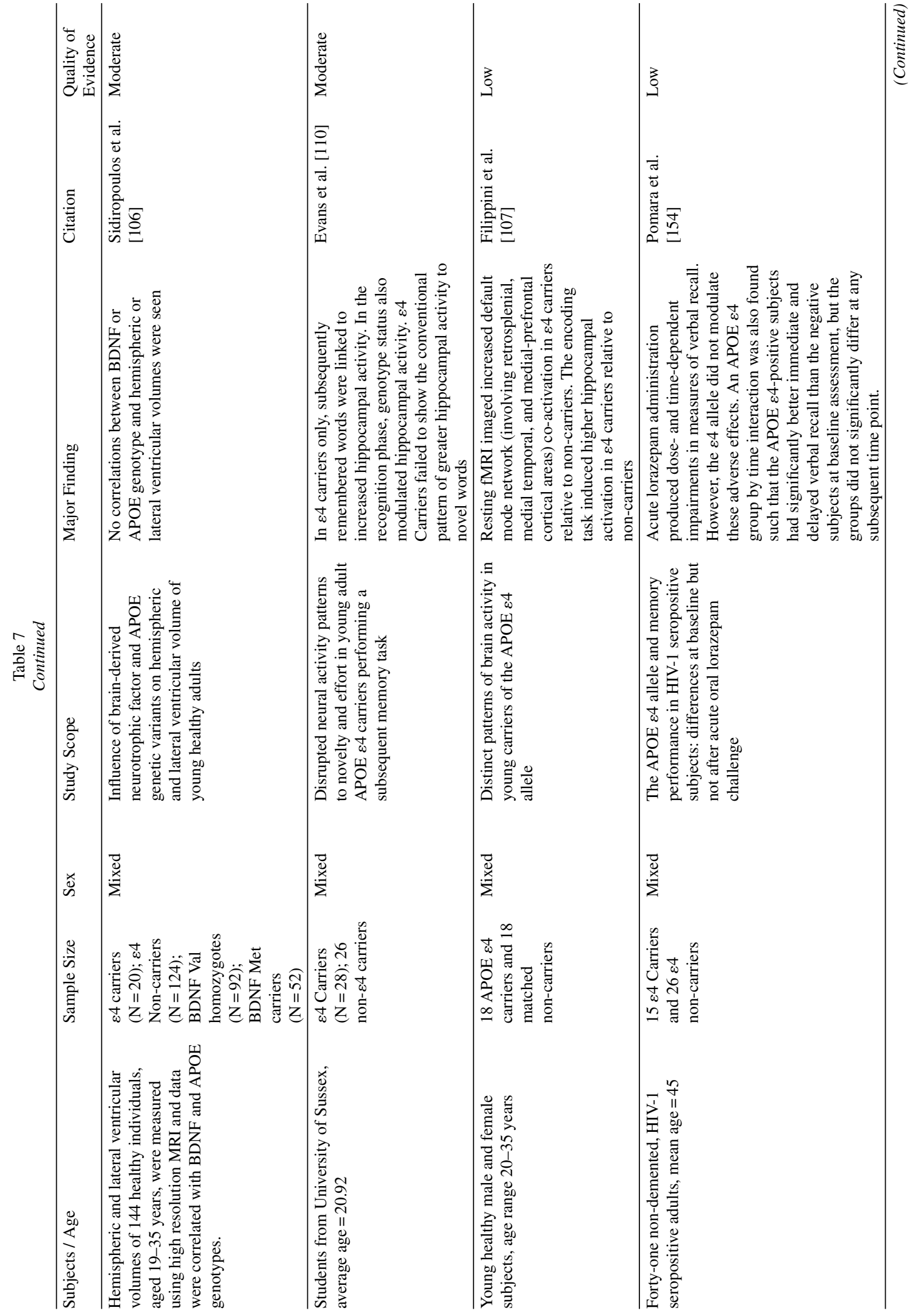




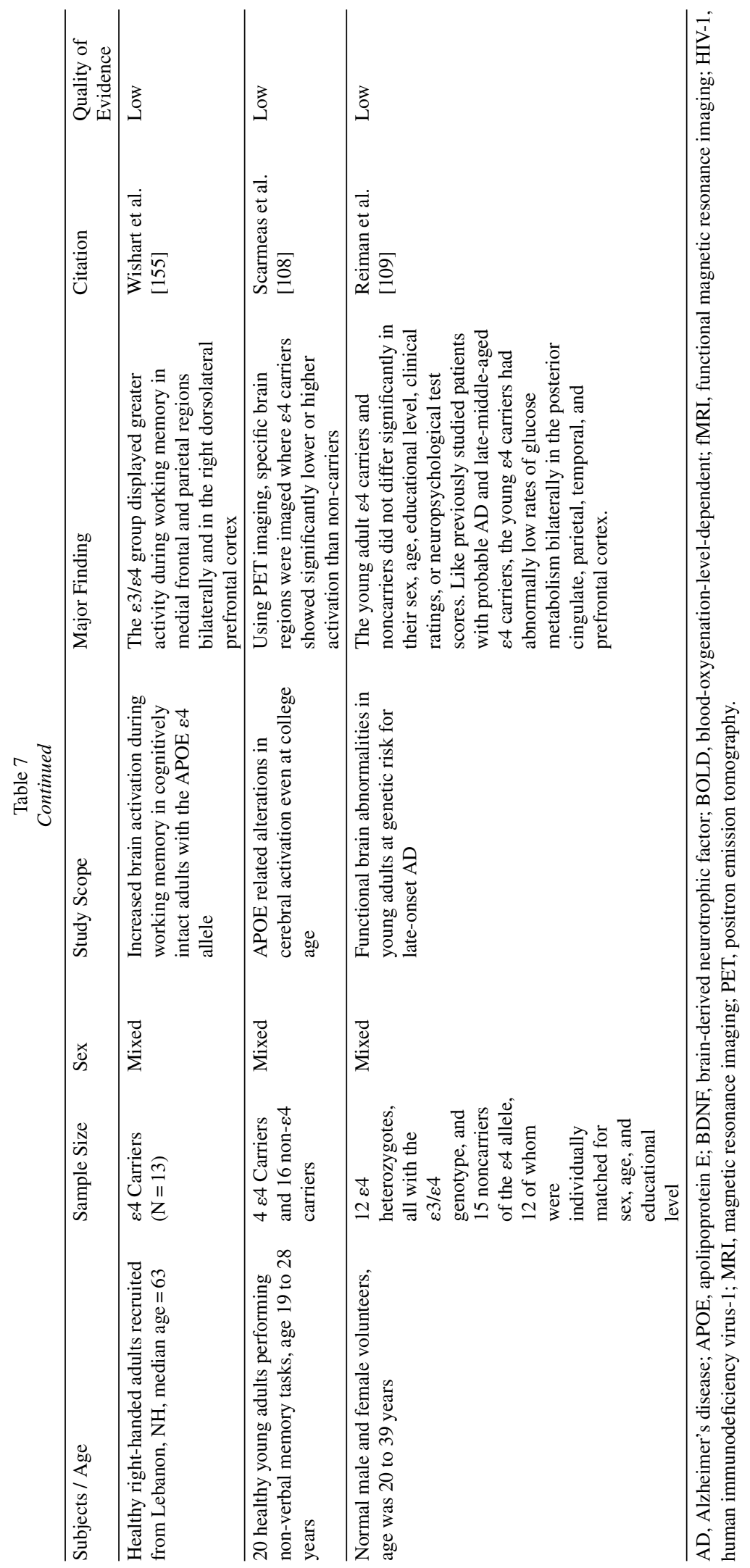




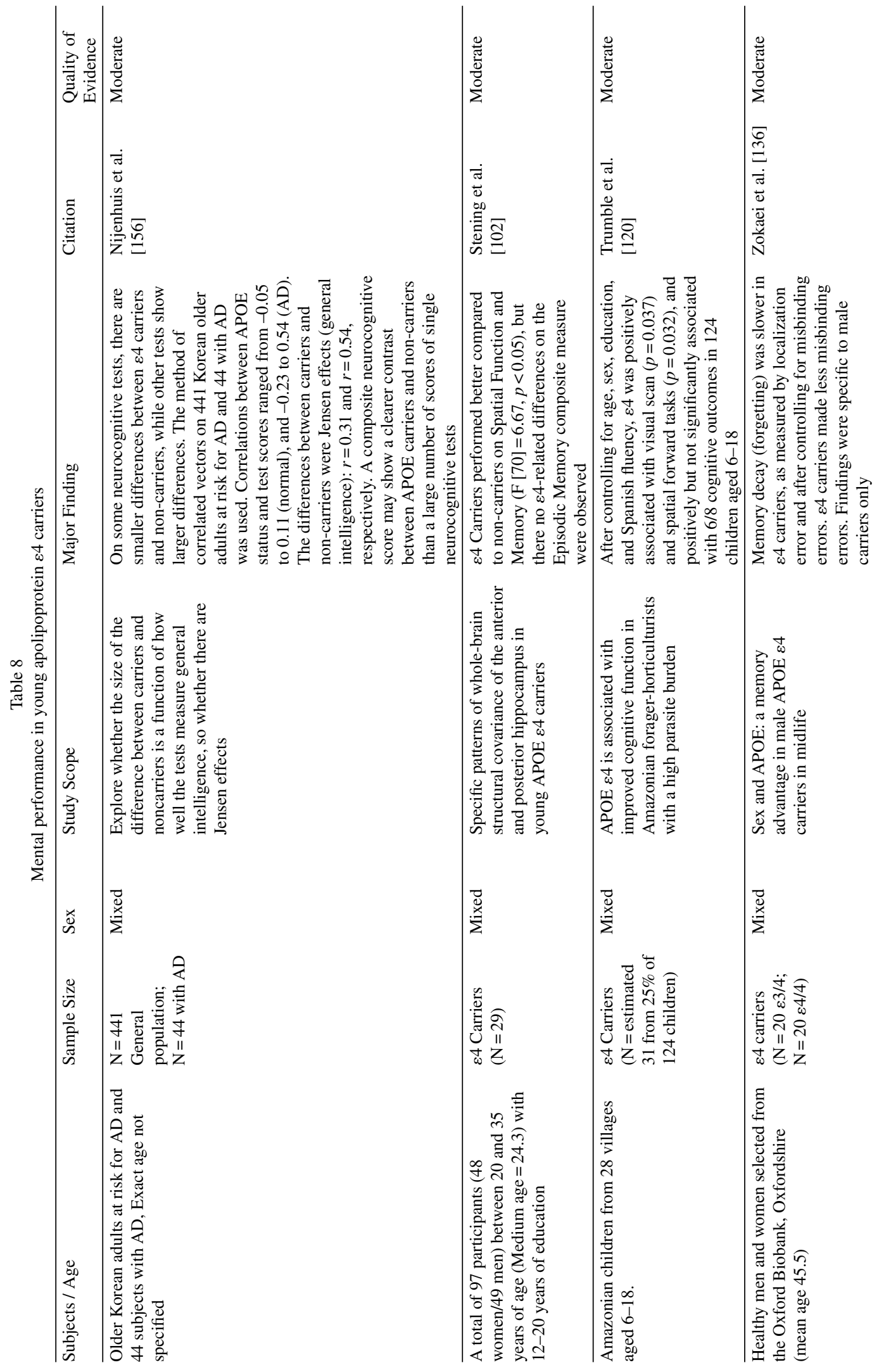




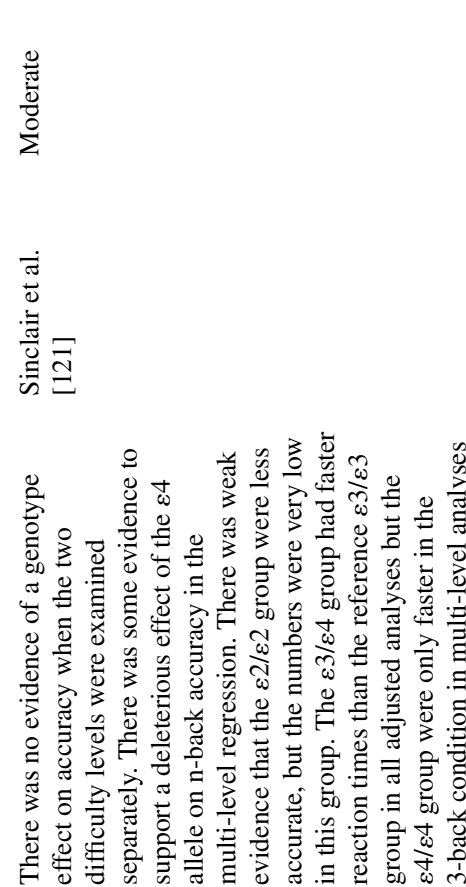

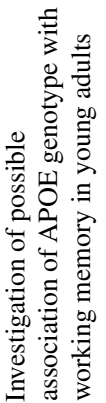

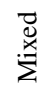

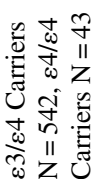

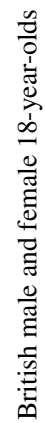

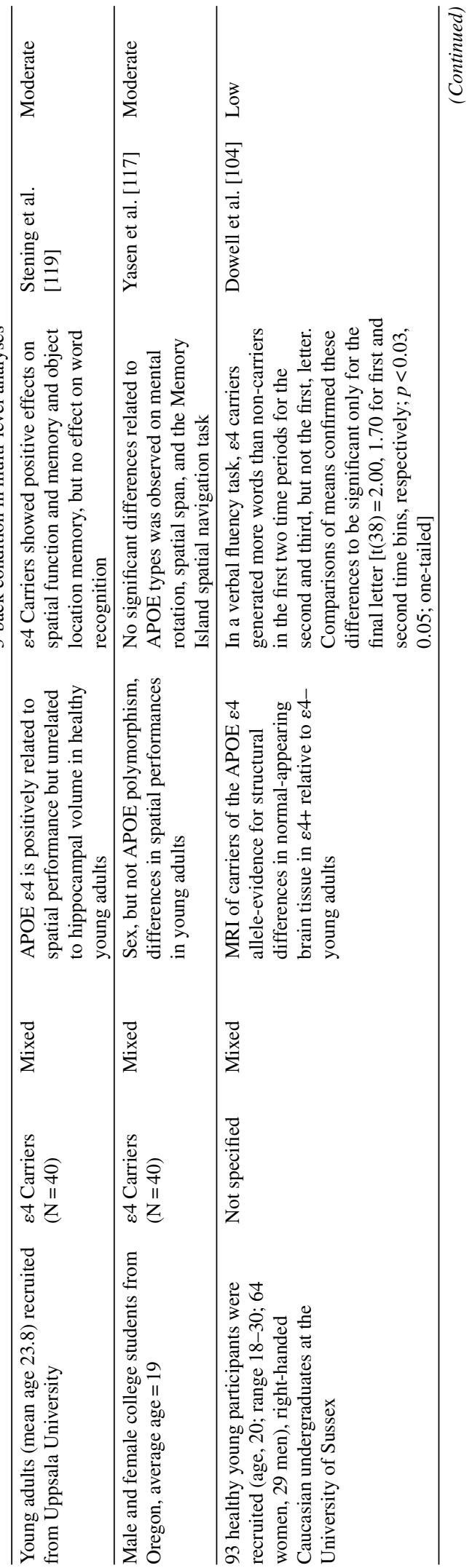




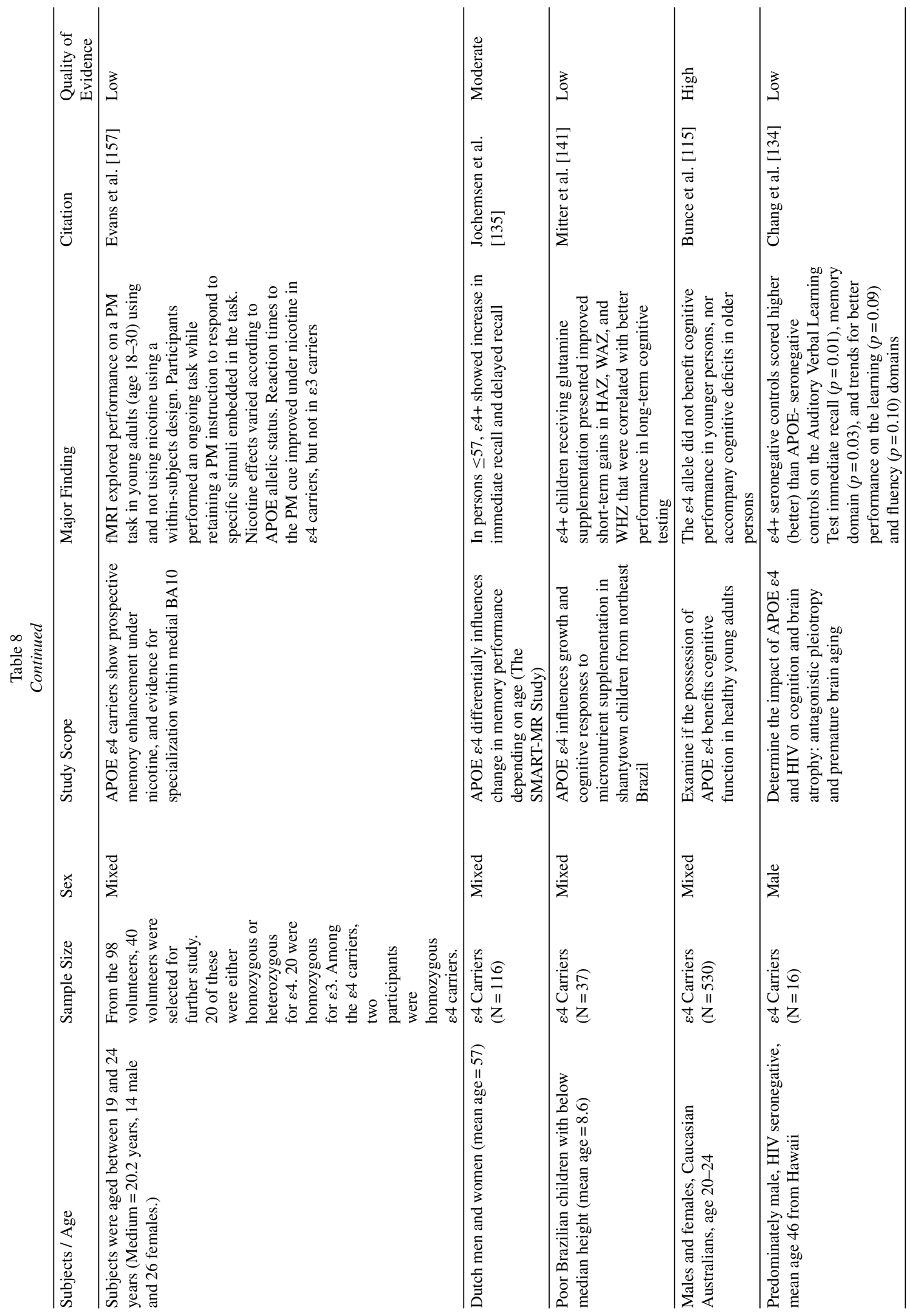




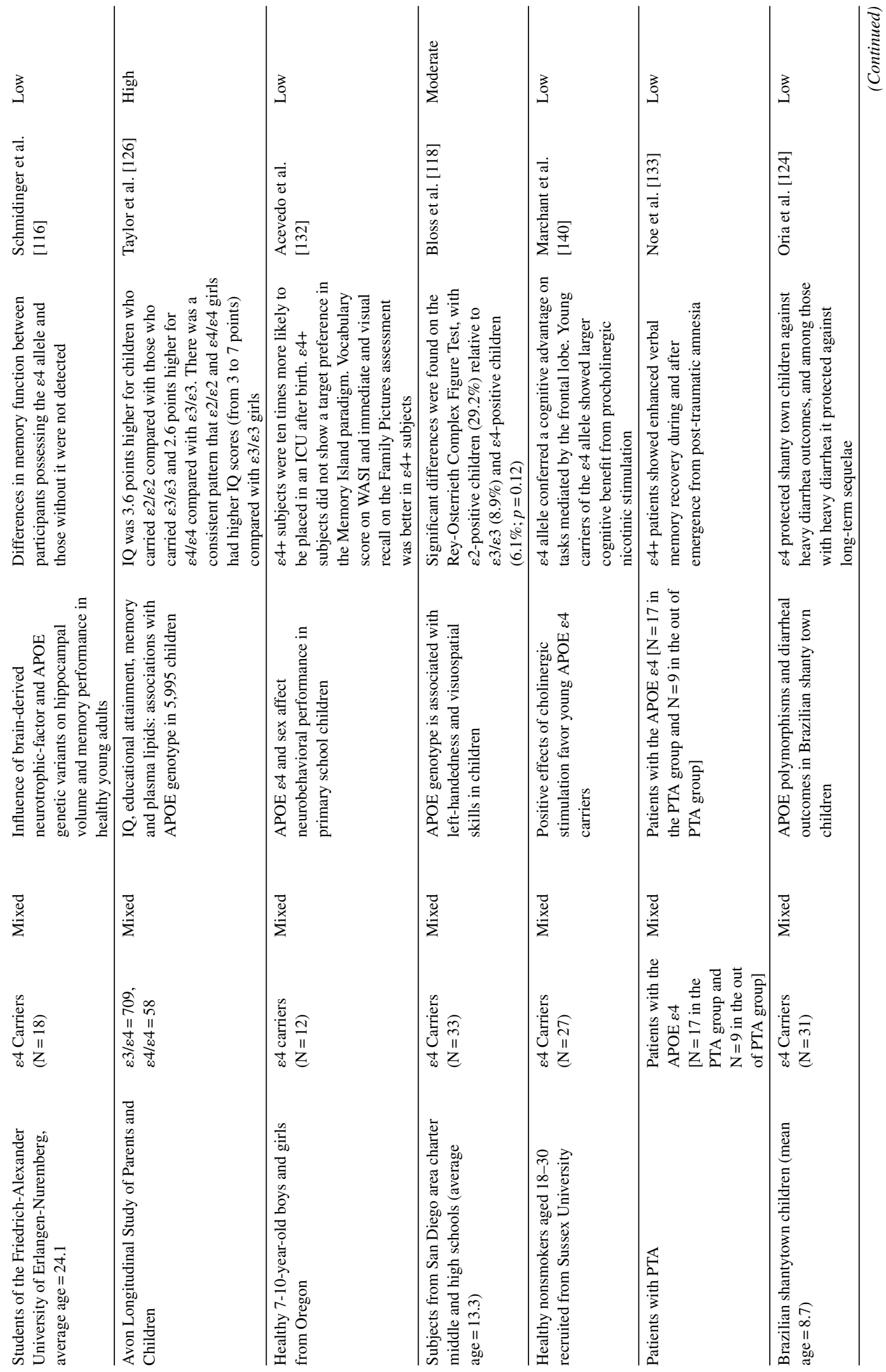




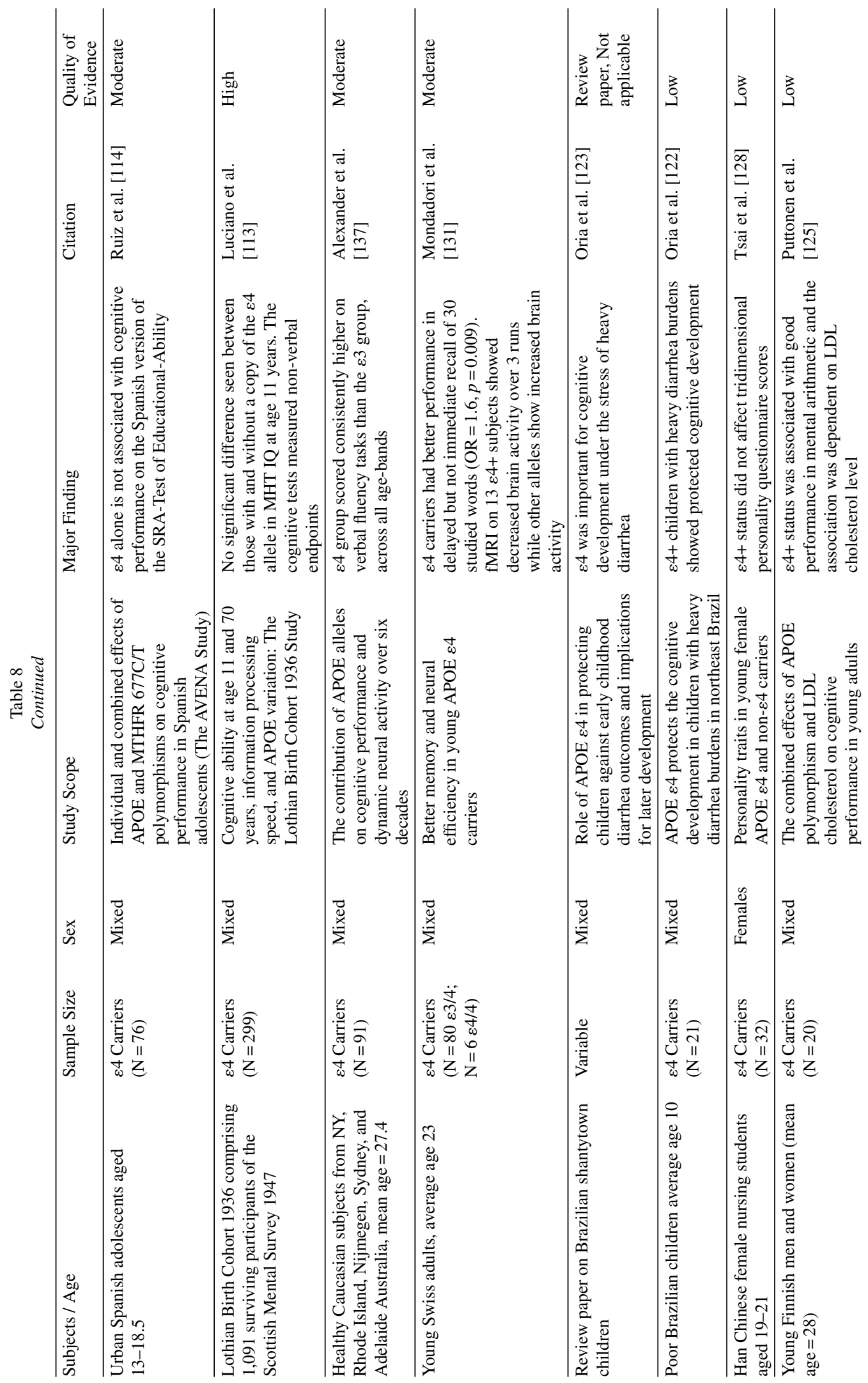




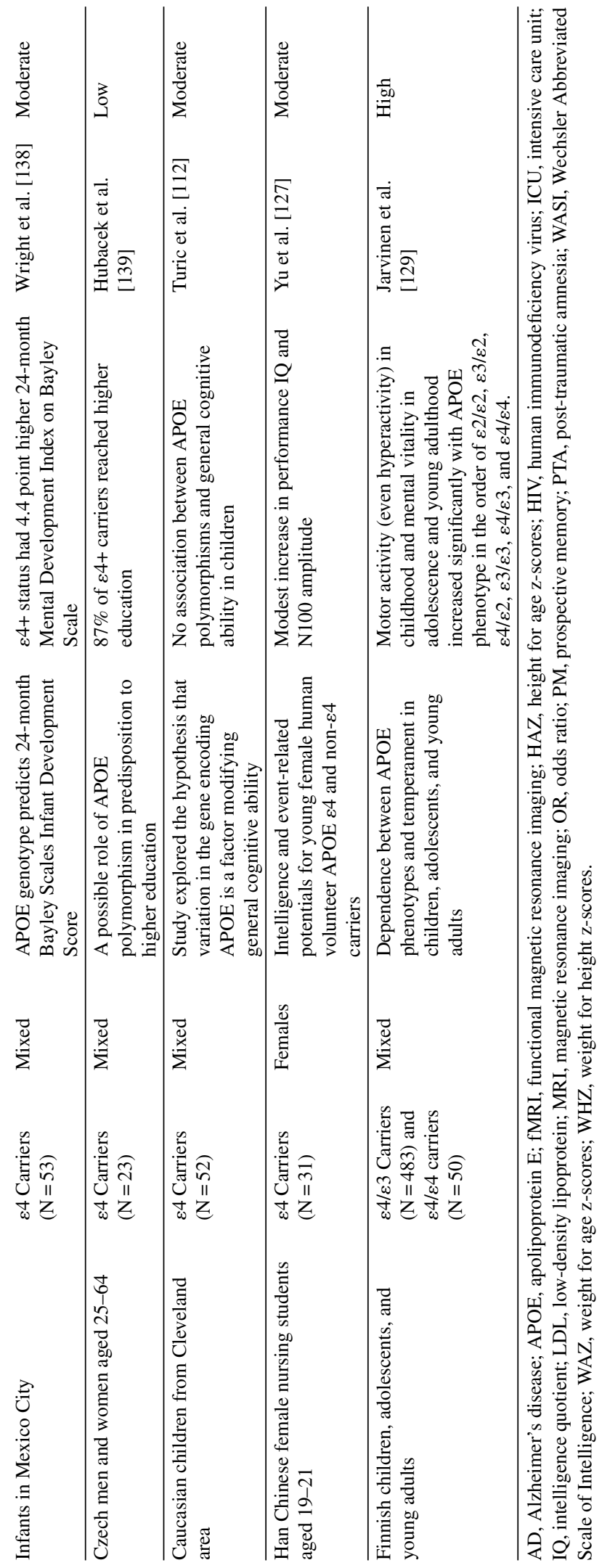


to the default action, $\beta$-secretase cleavage, then $\gamma$ secretase cleavage of the A $\beta P P$, with the end-products being fatal to that synapse. Note that the $\gamma$-secretase appears to act only on the $\beta$-secretase product and not on the $\alpha$-secretase product, producing both the $A \beta$ and an A $\beta P P$ intracellular domain (AICD) [24]. The AICD protein, acting intracellularly, leads to hyperphosphorylation of the critical structural protein of neuronal processes, microtubule associated protein tau [25]. The hyperphosphorylated tau appears to disrupt the normal flow in neuronal processes, leading to amputation [26]. The initial memory impairment of $\mathrm{AD}$ is likely due to the failure of the process for establishing new memory, while the dementia appears to develop when synaptic slaughter destroys large numbers of synapses [27], and loss of synapses is the factor most closely associated with the late progression of dementia [28]. Cholesterol metabolism, transport and processing might play a role in this process by affecting the composition of the neuronal synaptic membrane thereby altering its thickness. The extracellular region of A $\beta P P$ is much longer than the intracellular region. Small differences in the availability of enzymatic cleavage sites influenced by membrane thickness might have profound effects on the ultimate production of A $\beta P P$ sub-fragments [29, 30].

\section{IMPORTANCE OF THE APOE GENOTYPE}

The APOE genotype accounts for the vast majority of AD risk [31,32]. There are three common alleles of the APOE gene, i.e., APOE $\varepsilon 2$, APOE $\varepsilon 3$, and APOE $\varepsilon 4$ [33]. In the general US population, the $\varepsilon 4$ allele prevalence is approximately $13 \%$ [34], constituted by about $2 \%$ being $\varepsilon 4$ homozygous ( $2 \%$ of the US population) and $11 \%$ being heterozygous (22\% of the US population). Possession of one $\varepsilon 4$ allele increases the risk of developing $\mathrm{AD}$ by 3 to 4 -fold, and possession of two $\varepsilon 4$ alleles increases risk by 15 -fold, as compared with the $\varepsilon 3 / \varepsilon 3$ genotype, with a large part of the variation being related to substantially early age of onset, and over $60 \%$ of patients with non-familial AD carry the $\varepsilon 4$ allele $[35,36]$.

This profound difference in $\mathrm{AD}$ risk results from only minor changes in the structure of the APOE molecule. The three isoforms of APOE differ in amino acid sequence at only chain positions 112 and 158: the APOE $\varepsilon 2$ allele has cysteine at both positions; the APOE $\varepsilon 4$ allele has arginine at both positions; and the APOE $\varepsilon 3$ allele has cysteine at position 112 and arginine at 158 [37]. These small changes in amino acid sequence alter the biological activity of the APOE proteins in multiple ways, one of which is increased liver catabolism of the APOE $\varepsilon 4$ lipoprotein as compared with the APOE $\varepsilon 3$ lipoprotein $[38,39]$.

The strong positive association between possession of the $\varepsilon 4$ allele and the development of late-onset AD has stimulated extensive investigation on young, healthy subjects differing in APOE allele status. Numerous $\varepsilon 4$ allele-related associations have been reported in a series of epidemiological and clinical investigations on a variety of conditions, with the potential relevance of these associations to the pathogenesis of $\mathrm{AD}$ poorly understood at this time. Over the last several decades, numerous and elaborate interactions have been demonstrated between the nervous, immune, and endocrine systems [40]. This sophisticated system of sometimes centrally mediated biochemical cross-talk opens the possibility that an association between possession of the $\varepsilon 4$ allele and a particular clinical characteristic, condition, susceptibility or outcome might provide mechanistic information as to why allelic variation in a cholesterol metabolism gene is so strongly associated with the loss of synapses in the brain.

In primarily young subjects, we have attempted to review a representative body of literature on $\varepsilon 4$ allele-associations related to the following: cardiovascular responses; impacts on reproduction and fetal development; co-morbidities; resistance to infectious disease; responses to head injury; biochemical differences possibly related to neural stress; and brain structure-function differences. In addition, the literature on the association between the $\varepsilon 4$ allele and cognitive performance has been reviewed comprehensively. In each summary table, the ethnic composition, age, clinical diagnosis, and number of $\varepsilon 4$ carriers of the cohort studied are included.

\section{LITERATURE SEARCH STRATEGY}

Using Google and PubMed of the National Library of Medicine, the search terms apolipoprotein E or $\varepsilon 4$ allele were cross-matched against the terms: infant, youth, child, children, adolescent, or young. This initial search gathered a large number of potentially relevant citations that were categorized by clinical condition including cardiovascular responses; reproduction and development; co-morbidities; resistance to infectious disease; responses to head injury; 
biochemical differences possibly related to neural stress; brain structure-function; and mental performance. Each citation was physically collected, and the reference sections were manually checked for additional relevant citations until no further citations were found. No papers on the relevant topics were excluded. A few studies on middle age subjects not yet presenting with mild cognitive impairment were included with the aberrant age ranges clearly marked in the tables. The studies in the tables were not amenable to meta-analysis as the protocols were too heterogeneous. There were four referenced articles $([15,47,53,130])$ that included a meta-analysis. Some of the individual papers in the meta-analyses were also separately included in the review because the details in the individual papers were important.

\section{METHOD FOR GRADING QUALITY OF EVIDENCE}

As noted previously, the literature on associations between $\varepsilon 4$ status in otherwise healthy young subjects can be subdivided into several categories including: cardiovascular responses (Table 1); reproduction and development (Table 2); co-morbidities (Table 3); resistance to infectious disease (Table 4); responses to head injury (Table 5); biochemical differences possibly related to neural stress (Table 6); brain structure-function (Table 7); and mental performance (Table 8). Each table contains seven headings including sequentially: Subject/Age; Sample Size; Sex; Study Scope; Major Finding; Citation; and Quality of Evidence. The first six headings summarize the study characteristics, its results, and citation. The seventh heading provides the reader an estimate of the quality of evidence in the study based on a recognized evidence-based rating system.

A system developed by the Grading of Recommendations Assessment, Development and Evaluation Working Group (GRADE) for ranking the quality of evidence and the strength of recommendations of scientific literature and clinical practice guideline was applied to rate the studies found in Tables 1-8 [41]. The method described by Adkins et al. [41] was used to estimate the degree of confidence that can be placed on the evidence from research and clinical studies. The studies in the tables of this review represent a wide range of data (high to low) based on quality of evidence regarding main outcomes. The quality of evidence for each study was evaluated based on the following criteria.
- Study design (e.g., observational versus randomized trials);

- Study quality (i.e., detailed study methods and execution);

- Consistency (similarity of estimates of effects across like studies); and

- Directness (i.e., the extent to which the subjects, interventions, and outcomes measures are similar to those of interest).

The following definitions from the GRADE Working Group were used in grading the quality of the evidence based on the criteria above [41]:

- High $=$ Further research is very unlikely to change our confidence in the estimate of effect.

- Moderate $=$ Further research is likely to have an important impact on our confidence in the estimate of effect and may change the estimate.

- Low $=$ Further research is very likely to have an important impact on our confidence in the estimate of effect and is likely to change the estimate.

- Very low = Any estimate of effect is very uncertain.

It should be recognized that the ranking system is based on the quality of the evidence and not on the quality of the research, as all of the cited literature in this review was peer-reviewed.

\section{CARDIOVASCULAR RESPONSES IN YOUNG APOLIPOPROTEIN $\varepsilon 4$ CARRIERS (TABLE 1)}

The relationship between APOE allele type and cardiovascular risk factors and responses has been extensively studied. In a large study on Finnish boys and girls (Table 1), ages 3, 6, 9, 12, 15, and 18, including $28 \varepsilon 2 / \varepsilon 4$ carriers, $483 \varepsilon 3 / \varepsilon 4$ carriers, and $50 \varepsilon 4 / \varepsilon 4$ carriers, the concentrations of serum total cholesterol, low density lipoprotein cholesterol, and apolipoprotein B increased with APOE phenotype in the order of $\varepsilon 2 / \varepsilon 2, \varepsilon 3 / \varepsilon 2, \varepsilon 4 / \varepsilon 2, \varepsilon 3 / \varepsilon 3, \varepsilon 4 / \varepsilon 3$, and $\varepsilon 4 / \varepsilon 4$ [42]. In a follow-up study on Finnish male and female newborns and 3-year-old children including five $\varepsilon 2 / \varepsilon 4,147 \varepsilon 3 / \varepsilon 4$, and eight $\varepsilon 4 / \varepsilon 4$ carriers, the concentrations of serum total cholesterol and LDL cholesterol increased with APOE phenotype in the order of $\varepsilon 3 / \varepsilon 2, \varepsilon 3 / \varepsilon 3, \varepsilon 4 / \varepsilon 3$, and $\varepsilon 4 / \varepsilon 4$, in both males and females $(p<0.001)$ in the 3 -yearolds [43]. Another large study in 7- and 13-month-old Finnish infants included $36 \varepsilon 4 / \varepsilon 4$ and $209 \varepsilon 3 / \varepsilon 4$ 
carriers and reported that triglyceride concentrations were higher in infants with APOE $\varepsilon 4 / \varepsilon 4$ or $\varepsilon 3 / \varepsilon 4$ than in those with APOE $\varepsilon 3 / \varepsilon 3$ ( $p$-value for difference 0.01 and 0.009 , respectively) [44]. A smaller follow-up study was conducted on healthy 13 -monthold Finnish children and reported that 16 APOE $\varepsilon 4$ children had $30 \%$ to $50 \%$ higher cholesterol-adjusted campesterol and sitosterol concentrations in serum than 20 APOE $\varepsilon 3 / \varepsilon 3$ children ( $p=0.002$ and $p=0.02$, respectively) [45]. In $44 \varepsilon 4$ carrier Finnish infants, fed high-fat, high-cholesterol human milk, the total and LDL-cholesterol concentrations and the LDL APOB concentration of those with the APOE phenotype $\varepsilon 4 / \varepsilon 4$ or $\varepsilon 3 / \varepsilon 4$ rose faster and to higher levels than in other infants [46]. In a large study on 16-year-old Finnish boys and girls including $28 \varepsilon 2 / \varepsilon 4$ carriers, $470 \varepsilon 3 / \varepsilon 4$ carriers, and $49 \varepsilon 4 / \varepsilon 4$ carriers, physical exercise did not affect LDL cholesterol, total cholesterol, or HDL/total cholesterol in APOE $\varepsilon 4$ carriers [47]. In 1999, a study on Caucasian males in Perth, Australia, including eight pairs of $\varepsilon 3 / \varepsilon 3$ and $\varepsilon 4 / \varepsilon 4$ subjects matched for age and serum lipid levels, average age for the $\varepsilon 3 / \varepsilon 3=45$ and $\varepsilon 4 / \varepsilon 4=42$, suggested that inheritance of APOE $\varepsilon 4$ is associated with an increased affinity of VLDL particles for LDL receptors on hepatocytes [48].

Cardiovascular endpoints in addition to blood lipid levels have also been examined. $\varepsilon 3 / \varepsilon 2$ or $\varepsilon 3 / \varepsilon 3$ carriers showed marginally significantly greater heart rate reactivity and significantly greater task levels of heart rate and heart rate variability during mental stress than $\varepsilon 4 / \varepsilon 2, \varepsilon 4 / \varepsilon 3$, or $\varepsilon 4 / \varepsilon 4$ carriers among 28 healthy 16-year-old Finnish boys. The number of $\varepsilon 4$ carriers in this study was limited at only 11 [49]. Ellis et al. [50] studied 8-year-old children from the Tasmanian Infant Health Survey including $75 \varepsilon 4$ carriers and found that the $\varepsilon 4$ carriers had a lower body mass index and the effect was more evident among the less fit. In addition, Yu et al. [51] studied young adult Chinese men and women with an approximate mean age $=32 ; \varepsilon 3 / \varepsilon 4(\mathrm{~N}=60), \varepsilon 4 / \varepsilon 4(\mathrm{~N}=13)$. These authors found that $\mathrm{VO}_{2 \max }$ after exercise training increased significantly higher in carriers of $\varepsilon 3 / \varepsilon 4$ in males $(\mathrm{OR}=0.60,95 \% \mathrm{CI}=0.09-1.11 ; p=0.02)$ and females $(\mathrm{OR}=0.62,95 \% \mathrm{CI}=0.09-1.15 ; p=0.02)$. In summary, as compared with $\varepsilon 3$ carriers, young subjects possessing one or more $\varepsilon 4$ alleles show significant differences in total serum cholesterol, LDL, triglycerides, heart rate variability during mental stress, and $\mathrm{VO}_{2 \max }$. The directionality of the reported $\varepsilon 4$-associated lipid profiles is consistent with an increased risk of atherosclerosis later in life.

\section{Possible relationship of $\varepsilon 4$-related cardiovascular responses and $A D$}

As noted in the Introduction, cholesterol metabolism might play a role in slightly altering the thickness of the synaptic membrane. Synaptic membrane thickness could potentially affect the location of the cleavage site for $\gamma$-secretase $[29,30]$ A $\beta P P$ sub-fragments possibly being more potent for synaptic remodeling and learning, including playing a role in tau phosphorylation for synapse retraction, could also possess increased pathogenicity for the elderly, leading to tau hyperphosphorylation, the creation of paired-helical filaments, neuropil threads, and NFTs, with amputations of neuritic processes and massive destruction of synapses.

\section{REPRODUCTION AND DEVELOPMENT IN APOLIPOPROTEIN $\varepsilon 4$ CARRIERS (TABLE 2)}

A limited number of studies have examined potential associations between APOE $\varepsilon 4$ carrier status and fertility. In 2017, van Exel et al. [52] studied 100 women with a history of at least two firsttrimester recurrent miscarriages in Tabriz, Iran, and 100 healthy women with at least two successful pregnancies and no miscarriages. This study incorporated $31 \varepsilon 4$ carriers and showed that APOE $\varepsilon 4$ was associated with higher fertility in women exposed to high pathogen levels. In 2004, Corbo et al. [53] reported similar results in a population of Afro-Ecuadorian and Cayapa Indian women, average age $39 ; \varepsilon 4$ carriers $(\varepsilon 3 / \varepsilon 4=16 ; \varepsilon 4 / \varepsilon 4=6 ; \varepsilon 4 / \varepsilon 2=5)$. These authors reported that the $\varepsilon 3 / \varepsilon 4$ genotype frequency $(0.50)$ in the African-Ecuadorian women with 9-17 children was about three times that of the women with $0-8$ children $(0.14)(p=0.02)$. In contrast with these reportedly positive effects on fertility in populations without access to birth control methods, Gerdes et al. [54] studied a cohort of 40-year-old married men residing in Aarhus Denmark; $\varepsilon 4$ carriers $(\varepsilon 3 / \varepsilon 4=93$; $\varepsilon 4 / \varepsilon 4=12 ; \varepsilon 4 / \varepsilon 2=9$ ) and found that on average, men with the $\varepsilon 3 / \varepsilon 3$ genotype $(n=212)$ had 1.93 children, men with the $\varepsilon 3 / \varepsilon 4$ or $\varepsilon 2 / \varepsilon 2$ genotypes $(n=53)$ had 1.66 children. The potential confounding effects of the widespread availability of birth control methods in Denmark and the low average number of children per couple questions the clinical relevancy of these findings as per the association of the $\varepsilon 4$ allele and fertility.

Several studies have investigated the possible relationship between APOE $\varepsilon 4$ carrier status and 
occurrence of fetal miscarriages. A single study has reported a protective effect of the $\varepsilon 4$ allele [55]. Some studies do not report an association between $\varepsilon 4$ status and fetal loss [56-58]. At least five studies and one meta-analysis report a positive association between possession of the $\varepsilon 4$ allele and fetal loss [59-65]. Several additional studies have examined the association between $\varepsilon 4$ carrier status and a variety of pregnancyrelated conditions. Gaynor et al. [66] studied White, Black, and Hispanic neonates and infants; $\varepsilon 4$ carriers $(\mathrm{N}=87)$ and reported that the APOE $\varepsilon 2$ allele was associated with a lower Psychomotor Development Index $(p=0.038)$. Pregnant women with the $\varepsilon 4$ allele displayed an increased risk to develop Pregnancy Induced Hypertension (OR 4.14, $p=0.013$ ) and severe preeclampsia (OR 4.43, $p=0.019$ ) in a group of pregnant Romanian women, average age 28; $\varepsilon 4$ carriers $(\mathrm{N}=46)$ [67]. Cerebrospinal fluid (CSF) was collected from 107 healthy Japanese subjects (70 males, 37 females) aged 1-86 by Hirayama et al. [68] who showed that the APOE phenotype does not affect the composition or concentration of CSF high density lipoprotein in children. In 2003, Gaynor et al. [69] studied Asian, Black, and White, male and female infants under 6 months undergoing cardiac surgery in Philadelphia; $\varepsilon 4$ carriers $(\mathrm{N}=52)$ and reported that patients with the $\varepsilon 2$ allele had approximately a 7-point decrease in the Psychomotor Developmental Index [Bayley Scales of Infant Development] $(p=0.036)$.

In summary, the most notable findings related to fertility and the $\varepsilon 4$ allele suggest a protective effect of $\varepsilon 4^{+}$status and reproductive potential in populations exposed to high pathogen levels.

\section{Possible relationship between $\varepsilon$-related reproduction and development and $A D$}

The $\varepsilon 4$ allele is the ancestral allele to the now more common $\varepsilon 3$ allele. Protective effects on fertility and reproduction might help explain the original predominance of the $\varepsilon 4$ allele. The impetus for the conversion from $\varepsilon 4$ to $\varepsilon 3$ predominance is currently not understood.

\section{CO-MORBIDITIES IN YOUNG APOLIPOPROTEIN $\varepsilon 4$ CARRIERS (TABLE 3)}

A number of epidemiology studies have reported co-morbidities associated with possession of different APOE alleles (Table 1). Co-morbidities represent an important area of study as co-linearity in prevalence between clinical conditions of known etiology with clinical conditions whose current etiology is unknown (e.g., AD) might provide clues related to causation. A meta-analysis of 28 studies on schizophrenia reported a significant protective effect of $\varepsilon 3$ in an Asian population [70]. Another meta-analysis found a significant decrease in risk associated with each copy of $\varepsilon 4$ in all age-related macular degeneration sub-phenotypes [71]. A dermatology clinic in Spain reported that APOE $\varepsilon 4$ carriers were significantly more frequent in patients with severe psoriasis compared to controls $(p=0.003)$ and to non-severe psoriasis $(p=0.017)$. Infants with hypoxic-ischemic encephalopathy did not show an association with APOE allele type [72]. In contrast, the percentage of children with at least one $\varepsilon 4$ allele was significantly lower in non- Sudden infant death syndrome (SIDS) compared to SIDS $(p=0.016)$ in a study of infants from Scotland. Several studies have examined the potential relationship between APOE allele type and cerebral palsy. In children seen in Brasilia, Brazil, of whom 139 were $\varepsilon 4$ carriers, the presence of the $\varepsilon 2$ allele raised the probability of having cerebral palsy (OR 3.2; 95\% CI 1.27-8.27) while the APOE $\varepsilon 4$ allele was not significantly different among groups [73]. An earlier smaller study on Brazilian children that included only $13 \varepsilon 4$ carriers, reported a positive association between the $\varepsilon 4$ allele and cerebral palsy [74], as did a study on children from Chicago that included 25 $\varepsilon 4$ carriers [75].

\section{Possible relationship between 84 -related co-morbidities and $A D$}

The mechanism by which possession of the $\varepsilon 4$ allele exerts its increase risk of $\mathrm{AD}$ is currently unknown. Concomitantly, the mechanistic relationships between co-morbid clinical conditions and the $\varepsilon 4$ allele, and risk of $\mathrm{AD}$, are also not understood. As mechanistic relationships on $\mathrm{AD}$ causation are elucidated in the future, $\varepsilon 4$-related co-morbidities might provide additional mechanistic insights.

\section{RESISTANCE TO INFECTIOUS DISEASE IN APOLIPOPROTEIN $\varepsilon 4$ CARRIERS (TABLE 4)}

The potential relationship between resistance to infectious diseases and APOE allele status represents an important area of investigation as this 
environmental stressor can exert significant evolutionary pressures. The relationship between hepatitis $\mathrm{C}$ infection and APOE carrier status has been examined in several studies. Mueller et al. [76] enrolled 205 $\varepsilon 4$ carriers in two combined cohorts selected from patients from Charite Berlin and the University of Leipzig diagnosed with either chronic or self-limited hepatitis $\mathrm{C}$ virus infection. The average age of the patients was 48.7. These authors found that APOE $\varepsilon 4$ alleles were underrepresented in chronically hepatitis C-infected patients (10.2\%) compared to $13 \%$ in healthy controls $(p=0.001)$.

Male and female Caucasian Italian patients with chronic hepatitis $\mathrm{C}$, median age $=41 ; \varepsilon 2 / \varepsilon 4$ carriers $(\mathrm{N}=3), \varepsilon 3 / \varepsilon 4$ carriers $(\mathrm{N}=21), \varepsilon 4 / \varepsilon 4$ carriers $(\mathrm{N}=1)$ were studied by Fabris et al. [77]. They reported that patients not carrying an $\varepsilon 3$ allele, as well as carriers of a single $\varepsilon 3$ allele with serum cholesterol concentration $>190 \mathrm{mg} / \mathrm{dL}$ were more likely to have a favorable outcome regarding fibrosis progression with chronic hepatitis C. In an earlier study, Fabris et al. [78] investigated Italian male and female patients who underwent a cadaveric orthotopic liver transplantation, median age $55 ; \varepsilon 4$ carriers $(\mathrm{N}=34)$. Their results showed that possession of an APOE $\varepsilon 4$ allele to be associated with low fibrosis progression in recurrent hepatitis $\mathrm{C}$ infection, and with an idiosyncratic APOE-associated lipid profile. Price et al. [79] found that the APOE $\varepsilon 2$ and APOE $\varepsilon 4$ alleles were both associated with a reduced likelihood of chronic infection (hepatitis $\mathrm{C}$ virus). For $\varepsilon 2$, $\mathrm{OR}=0.39[95 \% \mathrm{CI}=0.211-0.728] \quad(p=0.003)$, and for $\varepsilon 4, \mathrm{OR}=0.6[95 \% \mathrm{CI}=0.38-0.96](p=0.032)$, in a study population of British and Irish Caucasian hepatitis $C$ patients; $\varepsilon 2$ carriers $(\mathrm{N}=48), \varepsilon 4$ carriers $(\mathrm{N}=84), 11$ carriers were both, i.e., $\varepsilon 2 / \varepsilon 4$. Twentyfour male and female patients, median age $=53.5$, with recurrent hepatitis $\mathrm{C}$ following cadaveric orthotopic liver transplantation; $\varepsilon 4$ carriers $(\mathrm{N}=12)$ of 48 donors, $\varepsilon 4$ carriers $(\mathrm{N}=17)$ of 48 recipients were studied by Toniutto et al. [80]. These authors found that recipient (but not donor) carriage of at least one $\varepsilon 4$ allele was associated with improvement in the staging score due exclusively to the contribution given by male recipients. Similarly, Wozniak et al. [81] observed British men and women with hepatitis $C$ viral infection, mean age $=41 ; \varepsilon 4$ carriers $(\mathrm{N}=42)$ and concluded that in chronically hepatitis $\mathrm{C}$ virus-infected subjects grouped according to extent of fibrosis, necroinflammation, and total Knodell score, an overrepresentation of the APOE $\varepsilon 4$ allele was found in those whose livers were mildly affected.
These authors suggested that carriage of an APOE4 $\varepsilon 4$ allele protects against severe liver damage induced by hepatitis $\mathrm{C}$ virus.

Although not as extensively studied as hepatitis $\mathrm{C}$ infection, the relationship between resistance to malaria and APOE allele status has also been examined in several studies. Fujioka et al. [82] showed that human plasma samples from APOE $\varepsilon 4 / \varepsilon 4$ but not APOE $\varepsilon 3 / \varepsilon 3$ donors inhibited growth and disrupted morphology of $P$. falciparum (malaria) in seven APOE $\varepsilon 4 / \varepsilon 4$ and six APOE $\varepsilon 3 / \varepsilon 3$ donors from Cleveland, OH, USA. Aucan et al. [83] observed Gambian children ages $1-10 ; \varepsilon 4$ carriers $(\mathrm{N}=244)$ and concluded that the APOE $\varepsilon 3 / \varepsilon 4$ genotype was found to be more common in children with both cerebral malaria and severe malarial anemia $(42.9 \%)$ than in controls $(24.8 \%)$ and mild malaria cases $(27.2 \%)$. When corrected for the number of clinical groups (4) compared with controls in this study, this finding was not statistically significant. An earlier study on African infants was reported by Wozniak et al. [84]. This group studied infants from Prampram, $50 \mathrm{~km}$ east of Accra on the south coast of Ghana; $\varepsilon 2 / \varepsilon 2$ carriers $(\mathrm{N}=4), \varepsilon 4$ carriers $(\mathrm{N}=47)$. Based on small numbers, APOE $\varepsilon 2$ homozygotes became infected with malaria at an earlier age than those carrying other genotypes.

At least one study on a potential relationship between APOE allele status and risk for development of herpes simplex encephalitis has been conducted in the United Kingdom [85]. These authors examined specimens from the brain or spleen of 14 patients with herpes simplex encephalitis and from the CSF of seven patients with HSV1 in their CSF detected by PCR. Lin et al. [85] concluded that APOE $\varepsilon 3$ and $\varepsilon 4$ allele frequencies did not differ significantly between the two groups, and that APOE $\varepsilon 2$ is a risk factor for herpes simplex encephalitis. In summary, possession of the $\varepsilon 4$ allele might provide some measure of protection against hepatitis $\mathrm{C}$ and malaria.

\section{Possible relationship between $\varepsilon 4$-related resistance to infectious disease and $A D$}

$\varepsilon 4$ allele-associated resistance to infectious diseases endemic in prehistoric populations is consistent with the ancestral predominance of the $\varepsilon 4$ allele. Evolutionary pressures or mechanisms that influenced the conversion of human populations from $\varepsilon 4$ predominance to $\varepsilon 3$ predominance remain unexplained. 


\section{RESPONSES TO HEAD INJURY IN YOUNG APOLIPOPROTEIN $\varepsilon 4$ CARRIERS (TABLE 5)}

Several studies have been conducted on the association between APOE allele frequency and either susceptibility to head injury, or recovery from head injury. In a 2018 study by Terrell et al. [86] on a cohort of male football and male and female soccer players (average age 19.85) from four US southern universities that enrolled $35 \varepsilon 4$ carriers, IL-6R CC was associated with a three times greater concussion risk and APOE $\varepsilon 4$ with a $40 \%$ lower risk. In a similar cohort with $62 \varepsilon 4$ carriers, Tierney et al. [87] found no significant association between carrying the $\varepsilon 4$ allele and history of concussion. However, Tierney et al. [87] stated that they assessed the medical history via researcher-assisted paper and pencil assessment, attempting to indicate the athlete's concussion history. Collegiate student athletes from the University of Toronto, average age 20.5, with $79 \varepsilon 4$ carriers were studied by Kristman et al. [88] with a small statistically significant positive association reported as stated by the authors of an unadjusted hazard ratio for concussion in the APOE $\varepsilon 4$ carriers of 1.18 (95\% CI: $0.52,2.69)$ compared to non-carriers. Adjusting for sex, weight, height, and team type resulted in an only slightly lower hazard ratio of 1.06 (95\% CI: $0.41,2.72$ ), indicating little effect from confounding factors. A somewhat larger study that relied upon self-reported concussion history over the previous eight years was conducted by Terrell et al. [89] on Black and White, male and female, college athletes from 23 schools, average age 19.7; $\varepsilon 3 / \varepsilon 4(\mathrm{~N}=225)$, $\varepsilon 4 / \varepsilon 4(\mathrm{~N}=20)$. Terrell et al. [89] summarized their results as showing no substantial evidence of an association between a history of concussion and APOE genotypes and haplotypes. However, the authors also noted that the cell sizes for some of the APOE genotypes were so small that meaningful analysis was not possible. Also, compared to those with the APOE $\varepsilon 3 / \varepsilon 3$ genotype, those with the $\varepsilon 2 / \varepsilon 3$ genotype were at a $60 \%$ higher risk for concussion, but the results were not statistically significant (OR, 1.6; 95\% CI, 0.5 to 4.8 ). In summary, the association between possession of the APOE $\varepsilon 4$ allele and risk of concussion is unclear at this time due to methodological limitations in determination of concussion history and limited sample sizes.

Han et al. [90] conducted a study on active duty military personnel with a recent history of mild to moderate traumatic brain injury, average age 22.6; $\varepsilon 4$ carriers $(\mathrm{N}=16)$. Their analysis showed comparable performances on most neuropsychological measures and better performances by $\varepsilon 4$ carriers on select measures of attention, executive functioning and episodic memory encoding. Merritt et al. [91] reported data on 53 veterans with a history of mild traumatic brain injury and 46 military controls and found that traumatic brain injury $\varepsilon 4$ carriers had relative impairments in memory function and speed of processing but not on executive function relative to traumatic brain injury-affected veterans without an $\varepsilon 4$ allele. However, there was no $\varepsilon 4$-related difference among the non-traumatic brain injury military controls.

In a relatively large study ( $\varepsilon 4$ carriers $\mathrm{N}=324$ ) enrolling consecutive head injury admissions (men and women) to a regional neurosurgical unit in West Scotland, average age 35, Teasdale et al. [92] found no overall association between APOE genotype and outcome. Thirty-six percent of APOE $\varepsilon 4$ carriers had an unfavorable outcome compared with $33 \%$ of noncarriers of APOE $\varepsilon 4$. This relatively large study was a follow-up to a smaller study conducted by Teasdale et al. in 1997 [93] on only $30 \varepsilon 4$ carriers. Another small study on $16 \varepsilon 3 / \varepsilon 4$ subjects recruited from a Canadian traumatic brain injury clinic who experienced mild to moderate traumatic brain injury, mean age 33, was conducted by Chamelian et al. [94]. These authors reported no association between the presence of the APOE $\varepsilon 4$ allele and poor outcome across all measures. In 2005, Blackman et al. [95] reviewed the childhood literature on APOE and brain injury up through 2005 and concluded that results from the limited studies in children were contrary to the adult experience with $\varepsilon 4$ seeming to confer protection for the brain whereas $\varepsilon 2$ posed a risk. Further larger studies are needed to definitively determine the role of APOE status on recovery from brain injury in young subjects.

\section{Possible relationship between $\varepsilon 4$-related responses to head injury and $A D$}

To date, a definitive relationship between $\varepsilon 4$ status and recovery from head injury has not been established. If $\varepsilon 4$ possession was established as associated with poor recovery from head injury, poor recovery could be consistent with an $\varepsilon 4$-associated increase in neural stress. Damage from accumulated neural stress might be a contributing factor to $\mathrm{AD}$. 


\section{BIOCHEMICAL DIFFERENCES POSSIBLY RELATED TO NEURAL STRESS IN APOLIPOPROTEIN $\varepsilon 4$ CARRIERS (TABLE 6)}

The strongest direct evidence that some of the macromolecular components comprising the synapses of $\varepsilon 4$ carriers might be turned over at a higher rate than comparable macromolecular synaptic components in non- $\varepsilon 4$ carriers has been provided by Yassine et al. [96]. This group studied 22 middleaged healthy adults (mean age 35 years, range 19-65 years) and found that $\mathrm{k}^{*}$, the mean global gray matter DHA incorporation coefficient, was significantly higher (16\%) among $\varepsilon 4$ carriers $(n=9)$ than among non-carriers $(n=13, p=0.046)$. Also in 2017 , the same group [13] reviewed original articles, systematic reviews, and meta-analyses of omega-3 studies in AD that were published before August 20, 2016 and concluded that while randomized clinical trials of omega-3 in symptomatic AD reported negative findings, several observational and clinical trials of omega-3 in the pre-dementia stage of AD suggest that omega-3 supplementation might slow early memory decline in $\varepsilon 4$ carriers. Tambini et al. [97] conducted an in vitro experiment whose results are consistent with the increased lipid metabolism observed by Yassine et al. [96]. Using an astrocyte-conditioned media model, this group measured the synthesis of phospholipids and cholesteryl esters and reported a significant increase in cells treated with APOE $\varepsilon 4$ containing astrocyte-conditioned media as compared to those treated with APOE $\varepsilon 3$-containing-astrocyteconditioned media.

Dose et al. [98] conducted a mini-review of APOE genotype and stress responses. From their analysis of the evidence on APOE isoform-dependent oxidative stress and mitochondrial function these authors concluded that APOE4 is associated with an increased stress response. Ramassamy et al. [99] conducted a brain tissue study whose results are consistent with the observations of Dose et al. [98]. They obtained human brain tissue from the Douglas Hospital Research Centre Brain Bank, Canada, average age 75-79; $\varepsilon 4$ carriers $(\mathrm{N}=18)$. Among $\varepsilon 4$ carriers with $\mathrm{AD}$, the levels of thiobarbituric acid-reactive substances were found to be higher among $\varepsilon 4$ carriers while the APOE protein concentrations were lower.

At least one small study has examined the potential association between vitamin D and APOE allele status [100]. In a sub-group of 93 subjects from a general population sample of 699 subjects (age of subjects unknown), multivariate adjusted modeling showed a positive association $(p=0.072)$ of the APOE $\varepsilon 4$ allele with 25(OH)D [vitamin D] levels. Another small study was conducted in 2012 by Ringman et al. [101] wherein thirty-three subjects were studied including six $\varepsilon 2 / \varepsilon 3$, six $\varepsilon 3 / \varepsilon 4$, and 21 $\varepsilon 3 / \varepsilon 4$ allele combinations. Plasma levels of APOE and superoxide dismutase 1 were lowest in $\varepsilon 4$ carriers, intermediate in $\varepsilon 3$ carriers, and highest in the $\varepsilon 2$ carriers. In contrast, multiple plasma interleukins were highest in $\varepsilon 4$ carriers and demonstrated significant negative correlations with age. Larger studies similar to those conducted by Yassine et al. would be helpful in clarifying the association of neural stress/macromolecular turnover rate with allele subtype.

\section{Possible relationship between $\varepsilon 4$-related biochemical changes related to neural stress and $A D$}

If the hippocampal neurons of two individuals possess the same susceptibility to an endogenous or exogenous stress factor, the neurons with the highest turnover of proteins, lipids, and other macromolecules might experience a larger integrated dose of detriment.

\section{BRAIN STRUCTURE-FUNCTION DIFFERENCES IN YOUNG APOLIPOPROTEIN $\varepsilon 4$ CARRIERS (TABLE 7)}

\section{Studies on brain structure}

Several studies have reported subtle differences in brain structure in association with APOE allele status. Stening et al. [102] studied $29 \varepsilon 4$ carriers in their subject population of 97 participants (48 women/49 men) between 20 and 35 years of age $(M=24.3)$ with $12-20$ years of education $(M=15)$. These authors reported the emergence of two different patterns. The first pattern showed that specific structural covariance of the anterior hippocampus and posterior hippocampus in all other groups co-varied with frontal, parietal and cerebellar areas. The second pattern displayed an opposite structural covariance of the posterior hippocampus in $\varepsilon 4$ carriers and the anterior hippocampus of $\varepsilon 4$ non-carriers co-varying with motor areas and the middle frontal gyrus. Given the small subject numbers, and uncertainty of the clinical significance of these differences in anatomic ratios, 
the relevance to the development of $\mathrm{AD}$ pathology and the later appearance of dementia is unknown.

A young group (average age 21) and a mid-age group (average age 50), of right-handed males and females with $21 \varepsilon 4$ carriers in the young group and 17 in the mid-age group $(\mathrm{N}=17)$ was investigated by Dowell et al. [103]. They found no detectable genotype-dependent differences in hippocampal volume for either the young or mid-aged adults. Also, the cuneus appeared to be an important locus for genotype differences with greater functional connectivity among young $\varepsilon 3 / \varepsilon 3$ individuals and greater white matter volume in young $\varepsilon 4^{+}$individuals. These authors also reported subtle cortical thickness measures in the parahippocampus in the young $\varepsilon 4^{+}$ individuals positively correlated with performance in a memory task. This 2016 study was a followup to an earlier study published by Dowell et al. [104]. The earlier 2013 study enrolled 93 healthy young participants (age, 20; range 18-30; 64 women, 29 men), right-handed Caucasian undergraduates at the University of Sussex. The authors summarized their results using voxel-based morphometry of highresolution structural MR images as identifying a higher white matter volume ratio in $\varepsilon 4$ relative to homozygous $\varepsilon 3$ carriers.

In 2011, Alexopoulos et al. [105] reported that healthy young APOE $\varepsilon 4$ carriers have statistically smaller hippocampal volumes than APOE $\varepsilon 2$ carriers. No differences were detected between the two groups in memory performance. The study population in Alexopoulos et al. [105] consisted of 33 healthy young German students, average age 24 , carrying either the APOE $\varepsilon 2$ or the $\varepsilon 4$ allele: $\varepsilon 2 / \varepsilon 3$ $(\mathrm{N}=15), \varepsilon 2 / \varepsilon 2(\mathrm{~N}=2), \varepsilon 3 / \varepsilon 4(\mathrm{~N}=12), \varepsilon 4 / \varepsilon 4(\mathrm{~N}=4)$.

In a study incorporating $20 \varepsilon 4$ carriers, Sidiropoulos et al. [106] found no correlations between brain derived neurotrophic factor (BDNF) or APOE genotype and hemispheric or lateral ventricular volumes. The study measured the hemispheric and lateral ventricular volumes of 144 healthy individuals, aged 19-35 years, using high resolution magnetic resonance imaging (MRI) and data were correlated with $\mathrm{BDNF}$ and APOE genotypes.

\section{Studies on brain function}

In addition to imaging studies that have been conducted on brain morphology, several studies have examined brain function in association with $\varepsilon 4$ carrier status. In 2009, Filippini et al. [107] conducted resting functional MRI (fMRI) on 18 young healthy male and female APOE $\varepsilon 4$ carriers and 18 matched noncarriers (age range 20-35). These authors observed increased default mode network (involving retrosplenial, medial temporal, and medial-prefrontal cortical areas) co-activation in $\varepsilon 4$ carriers relative to noncarriers. Also, the encoding task produced greater hippocampal activation in $\varepsilon 4$ carriers relative to noncarriers. Scarmeas et al. [108] studied 20 healthy young adults (age 19 to 28 years; four $\varepsilon 4$ carriers and 16 non- $\varepsilon 4$ carriers) during a non-verbal memory task. Using PET imaging, brain regions were identified where $\varepsilon 4$ carriers showed significantly lower or higher activation than non-carriers. Young $\varepsilon 4$ carriers had abnormally low rates of glucose metabolism bilaterally in the posterior cingulate, parietal, temporal, and prefrontal cortex in 139 20-39 age range, normal male and female volunteers, average age $31 ; \varepsilon 4$ carriers $(\mathrm{N}=12)$ [109]. The small subject numbers, high cost and labor intensity of imaging modalities, and heterogeneity of protocol design renders definitive interpretation of these structure and function studies problematic. However, lower brain metabolism in association with task performance can reasonably be assumed to represent a lower level of neural stress per unit time. Perhaps protocol design of imaging studies on metabolic demand should consider studying the brain areas recruited for tasks showing the greatest performance differential between $\varepsilon 3$ and $\varepsilon 4$ carriers.

Evans et al. [110] examined students from the University of Sussex, average age $=20.92 ; \varepsilon 4$ carriers $(\mathrm{N}=28)$. In $\varepsilon 4$ carriers only, these authors found that subsequently remembered words were linked to increased hippocampal activity. Additionally, Evans et al. reported that genotype status modulated hippocampal activity in the recognition phase [110]. Carriers of $\varepsilon 4$ did not show the conventional pattern of greater hippocampal activity to novel words.

Dennis et al. [111] enrolled 24 healthy young adults, 12 carriers and 12 non-carriers of the APOE $\varepsilon 4$ allele, and scanned them in a subsequent memory paradigm, using event-related fMRI. These authors reported that the APOE $\varepsilon 4$ allele carriers exhibited greater bilateral medial temporal lobe activity relative to the non-carriers to accomplish the same encoding task. In addition, $\varepsilon 4$ carriers demonstrated greater functional connectivity of encoding success activity-related medial temporal lobe activity with the posterior cingulate and other peri-limbic regions, with overall connectivity reductions found across anterior and posterior cortices. 


\section{Possible relationship between 84 -related brain structure and brain function and $A D$}

Preliminary imaging data suggest that certain brain regions related to memory processes might contain fewer neurons in carriers of the $\varepsilon 4$ allele than in noncarriers. Studies suggest the presence of increased mental performance in young healthy subjects who possess the $\varepsilon 4$ allele. Increased mental performance elicited from a reduced population of neurons might be exposing the young healthy $\varepsilon 4^{+}$brain to neural stress. The process of synaptic formation and normal homeostatic synaptic loss might be adversely impacted by long-term neural stress.

\section{MENTAL PERFORMANCE IN YOUNG APOLIPOPROTEIN $\varepsilon 4$ CARRIERS (TABLE 8)}

At least 32 studies or meta-analyses have examined mental performance in young APOE $\varepsilon 4$ carriers. No effect of the APOE allele was reported in six studies [112-117]. All six of the study populations reporting no effect were Caucasian and lived in the United States, United Kingdom, or Western Europe. A single study [118] on only $33 \varepsilon 4$ carriers reported inferior performance associated with possession of $\varepsilon 4$. Significant differences were found on the Rey-Osterrieth Complex Figure Test, with $\varepsilon 2$-positive children scoring $29.2 \%$ relative to $\varepsilon 3 / 3$ at $8.9 \%$ and $\varepsilon 4$-positive children at $6.1 \%(p=0.12)$.

Three studies reported improved performance in spatial tasks in $\varepsilon 4$ carriers [102, 119, 120]. A large British study $(\varepsilon 3 / 4=542, \varepsilon 4 / 4=43)$ showed faster reaction times in association with the $\varepsilon 4$ allele [121]. In a series of studies, Oria et al. [122-124] have shown that possession of the $\varepsilon 4$ allele protects against long-term cognitive deficits associated with severe diarrhea in Brazilian shanty-town children. In young Finnish men and women (mean age $=28$ ), $\varepsilon 4$ carriers $(\mathrm{N}=20), \varepsilon 4^{+}$status was associated with good performance in mental arithmetic and the association was dependent on LDL cholesterol level [125].

Two studies have reported a higher IQ in $\varepsilon 4$ carriers. In a large British study [126], there was a consistent pattern that $\varepsilon 2 / \varepsilon 2$ and $\varepsilon 4 / \varepsilon 4$ girls had higher IQ scores (from 3 to 7 points) compared with $\varepsilon 3 / \varepsilon 3$ girls. A small study (31 $\varepsilon 4$ carriers) on Han Chinese female nursing students showed a modest increase in performance IQ and N100 amplitude for $\varepsilon 4$ carriers ( $p=0.038$ and 0.068 , respectively) [127]. Using the same cohort of nursing students reported in $\mathrm{Yu}$ et al. [127], $\varepsilon 4^{+}$status did not affect tridimensional personality questionnaire scores [128]. In contrast with the lack of correlation with personality reported in the small cohort of Tsai et al. [128], a large study on Finnish children, adolescents, and young adults $[\varepsilon 4 / \varepsilon 3(\mathrm{~N}=483)$ and $\varepsilon 4 / \varepsilon 4(\mathrm{~N}=50)]$ reported that motor activity and even hyperactivity in childhood, and mental vitality in adolescence and young adulthood increased significantly in the order of $\varepsilon 2 / \varepsilon 2, \varepsilon 3 / \varepsilon 2, \varepsilon 4 / \varepsilon 2, \varepsilon 3 / \varepsilon 3, \varepsilon 4 / \varepsilon 3$, and $\varepsilon 4 / \varepsilon 4$ [129]. In addition, $\varepsilon 4$ carriers displayed a wider field of attention in two tasks [130].

Several studies have reported better performance on memory tasks in young subjects possessing the $\varepsilon 4$ allele [131-136]. Comparatively enhanced verbal fluency has also been observed in $\varepsilon 4$ allele carriers [137, 104]. In a study on 53 infants in Mexico City who were $\varepsilon 4$ carriers, $\varepsilon 4^{+}$status had a 4.4 point higher 24-month Mental Development Index on the Bayley Scale [138]. A small study from the Czech Republic on $23 \varepsilon 4^{+}$subjects suggested that early life cognitive advantages might persist through young adulthood as $87 \%$ of $\varepsilon 4^{+}$carriers reached higher education [139].

The results from two studies suggest that the cognitive response to particular pharmacologic agents might be affected by APOE $\varepsilon 4$ status. Twentyseven $\varepsilon 4$ carriers who were healthy nonsmokers, aged 18-30 recruited from Sussex University demonstrated that the $\varepsilon 4$ allele confers a cognitive advantage on tasks mediated by the frontal lobes. In addition, young carriers of the $\varepsilon 4$ allele show larger cognitive benefit from procholinergic nicotinic stimulation [140]. In the second study, poor Brazilian children with below median height (mean age $=8.6$ ), including $37 \varepsilon 4$ carriers reported that $\varepsilon 4^{+}$children receiving glutamine supplementation showed short-term gains in HAZ (height for age Z score), WAZ (weight for age $\mathrm{Z}$ score) and WHZ (weight for height $\mathrm{Z}$ score) that were correlated with better performance in long-term cognitive testing [141].

In this review of cognition and APOE allele genotype, our emphasis has been on $\varepsilon$-related clinical and performance associations in young rather than middle-age subjects. Several recent studies on middle age cohorts might address the issue of transition from $\varepsilon 4$-associated cognitive advantage to cognitive deficit. In an older cohort with an average age for $\varepsilon 4$ carriers of 58.0 and non-carriers of 61.4, Caselli et al. [142] sought to determine the age at presentation of $\varepsilon 4$-related declines in memory. They enrolled 815 subjects: $317 \varepsilon 4$ carriers, 79 of whom were $\varepsilon 4 / \varepsilon 4$ and $238 \varepsilon 3 / \varepsilon 4$. The non-carrier group 
contained 498 subjects. Carriers were followed for a longer period (5.3 versus 4.7 years, $p=0.01$ ), with an equivalent duration of formal education (15.4 years) and proportion of women (69\%). Longitudinal decline in memory in $\varepsilon 4$ carriers began before age 60 and showed greater acceleration than in noncarriers $(p=0.03)$. There was a possible $\varepsilon 4$ dose effect $(p=0.008)$. In 2017 , Lancaster et al. published a systematic and meta-analytic review of 36 studies on subjects ranging from 35-60 years old investigating APOE-related differences in cognition in mid-adulthood [143]. The average effect size of $\varepsilon 4$ status was non-significant across cognitive domains. Sinclair et al. [144] studied 114 participants with the allelic combinations of $\varepsilon 3 / \varepsilon 3$ (39 subjects), $\varepsilon 3 / \varepsilon 4$ (27 subjects), $\varepsilon 4 / \varepsilon 4$ (15 subjects), $\varepsilon 3 / \varepsilon 2$ (26 subjects), and $\varepsilon 2 / \varepsilon 2$ (7 subjects). The primary outcome was performance on the Rey Auditory Verbal Learning Test (RAVLT). $\varepsilon 2$ carriers displayed slightly better episodic memory performance $(p=0.016)$, somewhat improved n-back accuracy and better executive functioning $(p=0.005)$.

\section{Possible relationship between 84 -related increases in mental performance and $A D$}

The observation of increased mental performance in young healthy carriers of the $\varepsilon 4$ allele is consistent with the observation of increased brain lipid metabolism. Taken together, these observations suggest that macromolecular turnover rates related to synapse formation and loss might be elevated in these young $\varepsilon 4$ carriers. It is possible that a higher rate of synaptic turnover leads to increased accumulation of non-repaired molecular errors.

\section{CONCLUSIONS}

The weight-of-the-evidence presented in Tables 1-8 supports the hypothesis that the possession of the $\varepsilon 4$ allele in youth may have a positive differential impact on fitness during different life stages [145]. Young subjects having at least one copy of the $\varepsilon 4$ allele reportedly possess a number of advantages that might facilitate survival in harsh environments including the following among others: more rapid improvement in $\mathrm{VO}_{2 \max }$ following exercise [51]; increased fertility at high pathogen burdens $[52,53]$; more rapid infant development [105]; prophylaxis against cognitive deficits associated with severe diarrhea [122-124]; resistance to certain infections, e.g., hepatitis [76] and malaria [83]; faster reaction times
[121]; better spatial memory [111, 102, 119, 120]; and slight superiority in direct or indirect measures of IQ [135, 134, 126, 141]. Some of these advantages appear to come at the expense of differences in neural processing that might place higher metabolic demands per unit time on the brains of young $\varepsilon 4$ carriers $[143,111,96]$.

Until 300,000 years ago, ancestors of modern humans were ubiquitously $\varepsilon 4 / \varepsilon 4$ and then the $\varepsilon 3$ allele mutated from the ancestral $\varepsilon 4$ allele [146]. The $\varepsilon 3$ allele displayed a competitive survival advantage sufficiently robust to result in the current predominance of the $\varepsilon 3 / \varepsilon 3$ genotype which is now found in over $60 \%$ of the US population, presumably because of its protection for memory loss and dementia in progressively older age ranges [23]. Similarly, the $\varepsilon 2$ allele mutated from the $\varepsilon 3$ allele about 200,000 years ago, but this protective allele has remained relatively rare with the homozygous $\varepsilon 2 / \varepsilon 2$ variant less than $1 \%$, and the $\varepsilon 3 / \varepsilon 2$ heterozygote in about $11 \%$ of the population [144].

Given the ancestral primacy of the $\varepsilon 4$ allele, and the evolutionary trade-off of superior performance in youth versus additional years beyond historical lifespans, the abnormality of the $\varepsilon 4$ allele is somewhat a matter of perspective. If part of the APOE $\varepsilon 4$-associated neurotoxic susceptibility is based on pharmacokinetic rather than toxicant receptor interactions on a per mole basis [20], future therapies that slow down synaptic pruning might carefully consider differential effects based on APOE allele subtype. Current knowledge of potential sources of $\mathrm{AD}$ patient heterogeneity is lacking. Reducing at least one important source of inter-subject heterogeneity, i.e., APOE $\varepsilon 4$ allele carrier status, is advisable. Early attempts at shifting the balance away from synaptic pruning might consider enrolling early stage $\mathrm{AD}$ patients possessing at least one $\varepsilon 4$ allele.

\section{DISCLOSURE STATEMENT}

Authors' disclosures available online (https://www .j-alz.com/manuscript-disclosures/18-1089r3).

\section{REFERENCES}

[1] Jarvik L (1990) Alzheimer's original paper. Am J Psychiatry $147,127$.

[2] Blessed G, Tomlinson BE, Roth M (1968) The association between quantitative measures of dementia and of senile change in the cerebral grey matter of elderly subjects. $\mathrm{Br}$ J Psychiatry 114, 797-811. 
[3] Brun A, Gustafson L (1976) Distribution of cerebral degeneration in Alzheimer's disease. A clinicopathological study. Arch Psychiatr Nervenkr 223, 15-33.

[4] Braak H, Braak E (1996) Evolution of the neuropathology of Alzheimer's disease. Acta Neurol Scand Suppl 165, 312.

[5] Ashford JW, Shih WJ, Coupal J, Shetty R, Schneider A, Cool C, Aleem A, Kiefer VH, Mendiondo MS, Schmitt FA (2000) Single SPECT measures of cerebral cortical perfusion reflect time-index estimation of dementia severity in Alzheimer's disease. J Nucl Med 41, 57-64.

[6] Small GW, Kuhl DE, Riege WH, Fujikawa DG, Ashford JW, Metter EJ, Mazziotta JC (1989) Cerebral glucose metabolic patterns in Alzheimer's disease. Effect of gender and age at dementia onset. Arch Gen Psychiatry 46, 527-532.

[7] Langbaum JB, Chen K, Lee W, Reschke C, Bandy D, Fleisher AS, Alexander GE, Foster NL, Weiner MW, Koeppe RA, Jagust WJ, Reiman EM (2009) Categorical and correlational analyses of baseline fluorodeoxyglucose positron emission tomography images from the Alzheimer's Disease Neuroimaging Initiative (ADNI). Neuroimage 45, 1107-1116.

[8] Schwarz AJ, Yu P, Miller BB, Shcherbinin S, Dickson J, Navitsky M, Joshi AD, Devous MD, Sr., Mintun MS (2018) Regional profiles of the candidate tau PET ligand 18F-AV-1451 recapitulate key features of Braak histopathological stages. Brain 139, 1539-1550.

[9] Tosun D, Landau S, Aisen PS, Petersen RC, Mintun M, Jagust W, Weiner MW (2017) Association between tau deposition and antecedent amyloid-beta accumulation rates in normal and early symptomatic individuals. Brain 140, 1499-1512.

[10] Ashford JW, Kolm P, Colliver JA, Bekian C, Hsu LN (1989) Alzheimer patient evaluation and the mini-mental state: Item characteristic curve analysis. J Gerontol 44, P139-P146.

[11] Ashford JW (2008) Screening for memory disorders, dementia, and Alzheimer's disease. Aging Health 4, 399432.

[12] Ashford JW, Jarvik L (1985) Alzheimer's disease: Does neuron plasticity predispose to axonal neurofibrillary degeneration? N Engl J Med 313, 388-389.

[13] Ashford JW (2015) Treatment of Alzheimer's disease: The legacy of the cholinergic hypothesis, neuroplasticity, and future directions. J Alzheimers Dis 47, 149-156.

[14] Geddes JW, Tekirian TL, Soultanian NS, Ashford JW, Davis DG, Markesbery WR (1997) Comparison of neuropathologic criteria for the diagnosis of Alzheimer's disease. Neurobiol Aging 18, S99-105.

[15] Thal DR, Rub U, Orantes M, Braak H (2002) Phases of $\mathrm{A}$ beta-deposition in the human brain and its relevance for the development of AD. Neurology 58, 1791-1800.

[16] Nelson PT, Alafuzoff I, Bigio EH, Bouras C, Braak H, Cairns NJ, Castellani RJ, Crain BJ, Davies P, Del Tredici K, Duyckaerts C, Frosch MP, Haroutunian V, Hof PR, Hulette CM, Hyman BT, Iwatsubo T, Jellinger KA, Jicha GA, Kovari E, Kukull WA, Leverenz JB, Love S, Mackenzie IR, Mann DM, Masliah E, McKee AC, Montine TJ, Morris JC, Schneider JA, Sonnen JA, Thal DR, Trojanowski JQ, Troncoso JC, Wisniewski T, Woltjer RL, Beach TG (2012) Correlation of Alzheimer disease neuropathologic changes with cognitive status: A review of the literature. J Neuropathol Exp Neurol 71, 362-381.
[17] Brier MR, Gordon B, Friedrichsen K, McCarthy J, Stern A, Christensen J, Owen C, Aldea P, Su Y, Hassenstab J, Cairns NJ, Holtzman DM, Fagan AM, Morris JC, Benzinger TL, Ances BM (2016) Tau and Abeta imaging, CSF measures, and cognition in Alzheimer's disease. Sci Transl Med 8, 338-366.

[18] Farrell ME, Chen X, Rundle MM, Chan MY, Wig GS, Park DC (2018) Regional amyloid accumulation and cognitive decline in initially amyloid-negative adults. Neurology $\mathbf{9 1}$, e1809-e1821.

[19] Knopman DS, Petersen RC (2014) Mild cognitive impairment and mild dementia: A clinical perspective. Mayo Clin Proc 89, 1452-1459.

[20] Smith CJ, Ashford JW (2017) APOE $\varepsilon 4$ allele-associated Alzheimer's disease risk is consistent with increased lifetime exposure to a neurotoxic process. J Syst Integr Neurosci 3, 1-4.

[21] Vetrano DL, Rizzuto D, Calderón-Larrañaga A, Onder G, Welmer AK, Bernabei R, Marengoni A, Fratiglioni L (2018) Trajectories of functional decline in older adults with neuropsychiatric and cardiovascular multimorbidity: A Swedish cohort study. PLoS Med 15, e1002503.

[22] Eimer WA, Kumar D, Kumar V, Kumar N, Shanmugan N, Breakefield XO, Tanzi RE, Moir RD (2018) Alzheimer's disease-associated $\beta$-amyloid is rapidly seeded by Herpesviridae to protect against brain infection. Neuron $\mathbf{9 9}$, 56-63.

[23] Jones L, Holmans PA, Hamshere ML, Harold D, Moskvina V, Ivanov D, Pocklington A, Abraham R, Hollingworth P, Sims R, Gerrish A, Pahwa JS, Jones N, Stretton A, Morgan AR, Lovestone S, Powell J, Proitsi P, Lupton MK, Brayne C, Rubinsztein DC, Gill M, Lawlor B, Lynch A, Morgan K, Brown KS, Passmore PA, Craig D, McGuinness B, Todd S, Holmes C, Mann D, Smith AD, Love S, Kehoe PG, Mead S, Fox N, Rossor M, Collinge J, Maier W, Jessen F, Schürmann B, Heun R, Kölsch H, van den Bussche H, Heuser I, Peters O, Kornhuber J, Wiltfang J, Dichgans M, Frölich L, Hampel H, Hüll M, Rujescu D, Goate AM, Kauwe JS, Cruchaga C, Nowotny P, Morris JC, Mayo K, Livingston G, Bass NJ, Gurling H, McQuillin A, Gwilliam R, Deloukas P, Al-Chalabi A, Shaw CE, Singleton $\mathrm{AB}$, Guerreiro R, Mühleisen TW, Nöthen MM, Moebus S, Jöckel KH, Klopp N, Wichmann HE, Rüther E, Carrasquillo MM, Pankratz VS, Younkin SG, Hardy J, O'Donovan MC, Owen MJ, Williams J (2010) Genetic evidence implicates the immune system and cholesterol metabolism in the aetiology of Alzheimer's disease. PloS One 5, e13950.

[24] Flammang B, Pardossi-Piquard R, Sevalle J, Debayle D, Dabert-Gay AS, Thévenet A, Lauritzen I, Checler F (2012) Evidence that the amyloid- $\beta$ protein precursor intracellular domain, AICD, derives from $\beta$-secretase-generated C-terminal fragment. J Alzheimers Dis 30, 145-153.

[25] Ghosal K, Fan Q, Dawson HN, Pimplikar SW (2016) Tau protein mediates ABPP intracellular domain (AICD)induced Alzheimer's-like pathological features in mice. PLoS One 11, e0159435.

[26] Ashford JW, Soultanian NS, Zhang SX, Geddes JW (1998) Neuropil threads are collinear with MAP2 immunostaining in neuronal dendrites of Alzheimer brain. $J$ Neuropathol Exp Neurol 57, 972-978.

[27] Coleman PD, Yao PJ (2003) Synaptic slaughter in Alzheimer's disease. Neurobiol Aging 24, 1023-1027.

[28] Scheff SW, Price DA, Ansari MA, Roberts KN, Schmitt FA, Ikonomovic MD, Mufson EJ (2015) Synaptic change 
in the posterior cingulate gyrus in the progression of Alzheimer's disease. J Alzheimers Dis 43, 1073-1090.

[29] Song Y, Mittendorf KF, Lu Z, Sanders CR (2014) Impact of bilayer lipid composition on the structure and topology of the transmembrane amyloid precursor C99 protein. $J$ Am Chem Soc 136, 4093-4096.

[30] Winkler E, Kamp F, Scheuring J, Ebke A, Fukumori A, Steiner H (2012) Generation of Alzheimer diseaseassociated amyloid $\beta 42 / 43$ peptide by $\gamma$-secretase can be inhibited directly by modulation of membrane thickness. J Biol Chem 287, 21326-21334.

[31] Roses AD (1996) Apolipoprotein E alleles as risk factors in Alzheimer's disease. Annu Rev Med 47, 387-400.

[32] Raber J, Huang Y, Ashford JW (2004) APOE genotype accounts for the vast majority of $\mathrm{AD}$ risk and $\mathrm{AD}$ neuropathology. Neurobiol Aging 25, 641-650.

[33] Yassine HN, Braskie MN, Mack WJ, Castor KJ, Fonteh AN, Schneider LS, Harrington MG, Chui HC (2017) Association of docosahexaenoic acid supplementation with Alzheimer disease stage in apolipoprotein E E4 carriers. A review. JAMA Neurol 7, 339-347.

[34] Evans DA, Beckett LA, Field TS, Feng L, Albert MS, Bennett DA, Tycko B, Mayeux R (1997) Apolipoprotein E4 and incidence of Alzheimer disease in a community population of older persons. JAMA 277, 822-824.

[35] Ashford JW (2004) APOE genotype effects on Alzheimer's disease onset and epidemiology. J Mol Neurosci 23, 157-165.

[36] Corder EH, Saunders AM, Strittmatter WJ, Schmechel DE, Gaskell PC, Small GW, Roses AD, Haines JL, Pericak-Vance MA (1993) Gene dose of apolipoprotein E type 4 allele and risk of Alzheimer's disease in late onset families. Science 261, 921-923.

[37] Mahley RW, Weisgraber KH, Huang Y (2009) Apolipoprotein E: Structure determines function, from atherosclerosis to Alzheimer's disease to AIDS. J Lipid Res 50 (Suppl), S183-S188.

[38] Weisgraber KH (1990) Apolipoprotein E distribution among human plasma lipoproteins: Role of the cysteinearginine interchange at residue 112. J Lipid Res 31, 1503-1511.

[39] Polozova A, Salem N Jr (2007) Role of liver and plasma lipoproteins in selective transport of n-3 fatty acids to tissues: A comparative study of 14C-DHA and 3H-oleic acid tracers. J Mol Neurosci 33, 56-66.

[40] Taub DD (2008) Neuroendocrine interactions in the immune system. Cell Immunol 252, 1-6.

[41] Atkins D, Best D, Briss PA, Eccles M, Falck-Ytter Y, Flottorp S, Guyatt GH, Harbour RT, Haugh MC, Henry D, Hill S, Jaeschke R, Leng G, Liberati A, Magrini N, Mason J, Middleton P, Mrukowicz J, O'Connell D, Oxman AD, Phillips B, Schünemann HJ, Edejer T, Varonen H, Vist GE, Williams JW Jr, Zaza S (2004) Grading quality of evidence and strength of recommendations. BMJ 328, 1490-1493.

[42] Lehtimaki T, Moilanen T, Viikari J, Akerblom HK, Ehnholm C, Rönnemaa T, Marniemi J, Dahlen G, Nikkari T (1990) Apolipoprotein E phenotypes in Finnish youths: A cross-sectional and 6-year follow-up study. J Lipid Res 31, 487-495.

[43] Lehtimaki T, Porkka K, Viikari J, Ehnholm C, Akerblom HK, Nikkari T (1994) Apolipoprotein E phenotypes and serum lipids in newborns and 3-year-old children: The Cardiovascular Risk in Young Finns Study. Pediatrics 94, 489-493.
[44] Tammi A, Ronnemaa T, Viikari J, Jokinen E, Lapinleimu H, Ehnholm C, Simell O (2000) Apolipoprotein E4 phenotype increases non-fasting serum triglyceride concentration in infants - the STRIP study. Atherosclerosis 152, 135-141.

[45] Tammi A, Ronnemaa T, Nissila LR, Miettinen TA, Gylling H, Valsta L, Viikari J, Välimäki I, Simell O (2001) Apolipoprotein E phenotype regulates cholesterol absorption in healthy 13-month-old children - The STRIP Study. Pediatr Res 50, 688-691.

[46] Kallio MJT, Salmenpera L, Siimes MA, Perheentupa J, Gylling H, Miettinen TA (1997) Apolipoprotein E phenotype determines serum cholesterol in infants during both high-cholesterol breast feeding and low-cholesterol formula feeding. J Lipid Res 38, 759-764.

[47] Taimela S, Lehtimaki T, Porkka KVK, Rasanen L, Viikari JSA (1996) The effect of physical activity on serum total and low-density lipoprotein cholesterol concentrations varies with apolipoprotein E phenotype in male children and young adults: The Cardiovascular Risk in Young Finns Study. Metabolism 45, 797-803.

[48] Mamotte CDS, Sturm M, Foo JI, Van Bockxmeer FM, Taylor RR (1999) Comparison of the LDL-receptor binding of VLDL and LDL from APOE4 and APOE3 homozygotes. Am J Physiol 276(3 Pt 1), E553-557.

[49] Ravaja N, Raikkonen K, Lyytinen H, Lehtimake T, Jarvinen LK (1997) Apolipoprotein E phenotypes and cardiovascular responses to experimentally induced mental stress in adolescent boys. J Behav Med 20, 571-587.

[50] Ellis JA, Ponsonby AL, Pezic A, Williamson E, Cochrane JA, Dickinson JL, Dwyer T (2011) APOE genotype and cardio-respiratory fitness interact to determine adiposity in 8-year-old children from the Tasmanian Infant Health Survey. PLoS One 6, e26679.

[51] Yu B, Chen W, Wang R, Qi Q, Li K, Zhang W, Wang $\mathrm{H}$ (2014) Association of apolipoprotein E polymorphism with maximal oxygen uptake after exercise training: A study of Chinese young adult. Lipids Health Dis 13, 40.

[52] Van Exel E, Koopman JJE, Bodegom DV, Meij JJ, Knijff P, Ziem JB, Finch CE, Westendorp RGJ (2017) Effect of APOE E4 allele on survival and fertility in an adverse environment. PLoS One 12, e0179497.

[53] Corbo RM, Ulizzi L, Scacchi R, Labarga CM, Stefano GF (2004) Apolipoprotein E polymorphism and fertility: A study in pre-industrial populations. Mol Hum Reprod 10, 617-620.

[54] Gerdes LU, Gerdes C, Hansen PS, Klausen IC, Faergeman O (1996) Are men carrying the apolipoprotein E4- or E2 allele less fertile than E3E3 genotypes? Hum Genet 98, 239-242.

[55] Zetterberg H, Palmer M, Ricksten A, Poirier J, Palmqvist L, Rymo L, Zafiropoulos A, Arvanitis DA, Spandidos DA, Blennow K (2002) Influence of the apolipoprotein E E4 allele on human embryonic development. Neurosci Lett 324, 189-192.

[56] Agarwal M, Parveen F, Faridi RM, Phadke SR, Das V, Agrawal S (2010) Recurrent pregnancy loss and apolipoprotein E gene polymorphisms: A case-control study from North India. Am J Reprod Immunol 64, 172178.

[57] Bianca S, Barrano B, Cutuli N, Indaco L, Cataliotti A, Milana G, Barone C, Ettore G (2010) No association between apolipoprotein $\mathrm{E}$ polymorphisms and recurrent pregnancy loss. Fertil Steril 93, 276. 
[58] Korkmazer E, Ustunyurt E, Tekin B, Cilingir O (2013) Study on potential role of apolipoprotein $\mathrm{E}$ in recurrent pregnancy loss. Exp Ther Med 5, 1408-1410.

[59] Becher J-C, Keeling JW, Bell J, Wyatt B, McIntosh N (2008) Apolipoprotein E E4 and its prevalence in early childhood death due to sudden infant death syndrome or to recognized causes. Early Hum Dev 84, 549-554.

[60] Becher J-C, Keeling JW, McIntosh N, Wyatt B, Bell J (2006) The distribution of apolipoprotein E alleles in Scottish perinatal deaths. J Med Genet 43, 414-418.

[61] Goodman C, Goodman CS, Hur J, Jeyendran RS, Coulam C (2009) The association of apoprotein E polymorphisms with recurrent pregnancy loss. Am J Reprod Immunol 61, 34-38.

[62] Ozornek H, Ergin E, Jeyendran RS, Ozay AT, Pillai D, Coulam C (2010) Is apolipoprotein E codon 112 polymorphisms associated with recurrent pregnancy loss? Am J Reprod Immunol 64, 87-92.

[63] Asgari N, Akbari MT, Zare S, Babamohammadi G (2013) Positive association of apolipoprotein E4 polymorphism with recurrent pregnancy loss in Iranian patients. J Assist Reprod Genet 30, 265-268.

[64] Meng HX, Qi MG, Yi YY, Liu YP (2013) Association between apolipoprotein $\mathrm{E}$ gene polymorphism and the risk of recurrent pregnancy loss: A meta-analysis. J Assist Reprod Genet 30, 1547-1552.

[65] Zonouzi AP, Farajzadeh D, Bargahi N, Farajzadeh M (2014) Apolipoprotein E genotyping in women with recurrent pregnancy loss: An in silico and experimental hybrid study. Gene 549, 209-213.

[66] Gaynor JW, Kim DS, Arrington CB, Atz AM, Bellinger DC, Burt AA, Ghanayem NS, Jacobs JP, Lee TM, Lewis AB, Mahle WT, Marino BS, Miller SG, Newburger JW, Pizarro C, Ravishankar C, Santani AB, Wilder NS, Jarvik GP, Mital S, Russell MW (2014) Validation of association of the apolipoprotein E E2 allele with neurodevelopmental dysfunction after cardiac surgery in neonates and infants. J Thorac Cardiovasc Surg 148, 2560-2568.

[67] Procopciuc LM, Hazi GM, Caracostea G, Nemeti G, Olteanu H, Stamatian F (2011) Apolipoprotein E polymorphism - a risk factor in Romanian pregnant women with preeclampsia. Obstetrics 7, 134-140.

[68] Hirayama S, Miida T, Obayashi K, Yamazaki F, YamazakiSakurai M, Ito M, Saito Y, Hanyu O, Suzuki K, Aizawa Y (2005) Effect of apolipoprotein E (APOE) phenotype on the APOE content of CSF-HDL in children. Clin Chim Acta 356, 110-116.

[69] Gaynor JW, Gerdes M, Zackai EH, Bernbaum J, Wernovsky G, Clancy RR, Newman MF, Saunders AM, Heagerty PJ, D'Agostino JA, McDonald-McGinn D, Nicolson SC, Spray TL, Jarvik GP (2003) Apolipoprotein E genotype and neurodevelopmental sequelae of infant cardiac surgery. J Thorac Cardiovasc Surg 126, 17361745 .

[70] González-Castro TB, Tovilla-Zárate CA, Hernández-Díaz Y, Fresán A, Juárez-Rojop IE, Ble-Castillo JL, LópezNarváez L, Genis A, Hernández-Alvarado MM (2015) No association between APOE and schizophrenia: Evidence of systematic review and updated meta-analysis. Schizophr Res 169, 355-368.

[71] McKay GJ, Patterson CC, Chakravarthy U, Dasari S, Klaver CC, Vingerling JR, Ho L, de Jong PT, Fletcher AE, Young IS, Seland JH, Rahu M, Soubrane G, Tomazzoli L, Topouzis F, Vioque J, Hingorani AD, Sofat R, Dean M, Sawitzke J, Seddon JM, Peter I, Webster AR, Moore AT,
Yates JR, Cipriani V, Fritsche LG, Weber BH, Keilhauer CN, Lotery AJ, Ennis S, Klein ML, Francis PJ, Stambolian D, Orlin A, Gorin MB, Weeks DE, Kuo CL, Swaroop A, Othman M, Kanda A, Chen W, Abecasis GR, Wright AF, Hayward C, Baird PN, Guymer RH, Attia J, Thakkinstian A, Silvestri G (2011) Evidence of association of APOE with age-related macular degeneration - a pooled analysis of 15 studies. Hum Mutat 32, 1407-1416.

[72] Cotten CM, Goldstein RF, McDonald SA, Goldberg RN, Salhab WA, Carlo WA, Tyson JE, Finer NN, Walsh MC, Ehrenkranz RA, Laptook AR, Guillet R, Schibler K, Van Meurs KP, Poindexter BB, Stoll BJ, O'Shea TM, Duara S, Das A, Higgins RD, Shankaran S (2014) Apolipoprotein E (APOE) genotype and outcome in infants with hypoxicischemic encephalopathy (HIE). Pediatr Res 75, 424-430.

[73] Braga LW, Borigato EV, Speck-Martins CE, Imamura EU, Gorges AM, Izumi AP, Dantas RC, Nunes LG (2010) Apolipoprotein E genotype and cerebral palsy. Dev Med Child Neurol 52, 666-671.

[74] De Barros EMKP, Rodrigues CJ, de Barros TEP, Bevilacqua RG (2000) Presence of apolipoprotein E E4 allele in cerebral palsy. J Pediatr Orthop 20, 786-789.

[75] Kuroda MM, Weck ME, Sarwark JF, Hamidullah A, Wainwright MS (2007) Association of apolipoprotein E genotype and cerebral palsy in children. Pediatrics 119, 306-313.

[76] Mueller T, Fischer J, Gessner R, Rosendahl J, Böhm S, van Bömmel F, Knop V, Sarrazin C, Witt H, Marques AM, Kovacs P, Schleinitz D, Stumvoll M, Blüher M, Bugert P, Schott E, Berg T (2016) Apolipoprotein E allele frequencies in chronic and self-limited hepatitis $C$ suggest a protective effect of APOE4 in the course of hepatitis C virus infection. Liver Int 36, 1267-1274.

[77] Fabris C, Vandelli C, Toniutto P, Minisini R, Colletta C, Falleti E, Smirne C, Pirisi M (2011) Apolipoprotein E genotypes modulate fibrosis progression in patients with chronic hepatitis $\mathrm{C}$ and persistently normal transaminases. Hepatology 26, 328-333.

[78] Fabris C, Toniutto P, Bitetto D, Minisini R, Smirne C, Caldato M, Pirisi M (2005) Low fibrosis progression of recurrent hepatitis C in apolipoprotein E E4 carriers: Relationship with the blood lipid profile. Liver Int 25, 1128-1135.

[79] Price DA, Bassendine MF, Norris SM, Golding C, Toms GL, Schmid ML, Morris CM, Burt AD, Donaldson PT (2006) Apolipoprotein E3 allele is associated with persistent hepatitis C virus infection. Gut 55, 715-718.

[80] Toniutto P, Fabris C, Fumo E, Apollonio L, Caldato M, Mariuzzi L, Avellini C, Minisini R, Pirisi M (2004) Carriage of the apolipoprotein E-E4 allele and histologic outcome of recurrent hepatitis $\mathrm{C}$ after antiviral treatment. Am J Clin Pathol 122, 428-433.

[81] Wozniak MA, Itzhaki RF, Faragher EB, James MW, Ryder SD, Irving WL (2002) Apolipoprotein E-E4 protects against severe liver disease caused by hepatitis $\mathrm{C}$ virus. Hepatology 36, 456-463.

[82] Fujioka H, Phelix CF, Friedland RP, Zhu X, Perry EA, Castellani RJ, Perry G (2013) Apolipoprotein E4 prevents growth of malaria at the intraerythrocyte stage: Implications for differences in racial susceptibility to Alzheimer's disease. J Health Care Poor Underserved 24(4 Suppl), 70-78.

[83] Aucan C, Walley AJ, Hill AVS (2004) Common apolipoprotein $\mathrm{E}$ polymorphisms and risk of clinical malaria in the Gambia. J Med Genet 41, 21-24. 
[84] Wozniak MA, Faragher EB, Todd JA, Koram KA, Riley EM, Itzhaki RF (2003) Does apolipoprotein E polymorphism influence susceptibility to malaria? J Med Genet $\mathbf{4 0}$, 348-351.

[85] Lin WR, Wozniak MA, Esiri MM, Klenerman P, Itzhaki RF (2001) Herpes simplex encephalitis: Involvement of apolipoprotein E genotype. J Neurol Neurosurg Psychiatry 70, 117-119.

[86] Terrell TR, Abramson R, Barth JT, Bennett E, Cantu RC, Sloane R, Laskowitz DT, Erlanger DM, McKeag D, Nichols G, Valentine V, Galloway L (2018) Genetic polymorphisms associated with the risk of concussion in 1056 college athletes: A multicenter prospective cohort study. Br J Sports Med 52, 192-198.

[87] Tierney RT, Mansell JL, Higgins M, McDevitt JK, Toone N, Gaughan JP, Mishra A, Krynetskiy E (2010) Apolipoprotein E genotype and concussion in college athletes. Clin J Sport Med 20, 464-468.

[88] KristmanVL, Tator CH, Kreiger N, Richards D, Mainwaring L, Jaglal S, Tomlinson G, Comper P (2008) Does the apolipoprotein $\mathrm{E} 4$ allele predispose varsity athletes to concussion? A prospective cohort study. Clin J Sport Med 18, 322-328.

[89] Terrell TR, Bostick RM, Abramson R, Xie D, Barfield W, Cantu R, Stanek M, Ewing T (2008) APOE, APOE promoter, and TAU genotypes and risk for concussion in college athletes. Clin J Sport Med 18, 10-17.

[90] Han SD, Drake AI, Cessante LM, Jak AJ, Houston WS, Delis DC, Filoteo JV, Bondi MW (2007) Apolipoprotein $\mathrm{E}$ and traumatic brain injury in a military population: Evidence of a neuropsychological compensatory mechanism? J Neurol Neurosurg Psychiatry 78, 1103-1108.

[91] Merritt VC, Clark AL, Sorg SF, Evangelista ND, Werhane ML, Bondi MW, Schiehser DM, Delano-Wood L (2018) Apolipoprotein E (APOE) $\varepsilon 4$ genotype is associated with reduced neuropsychological performance in military veterans with a history of mild traumatic brain injury. J Clin Exp Neuropsychol 40, 1050-1061.

[92] Teasdale GM, Murray GD, Nicoll JAR (2005) The association between APOE E4, age and outcome after head injury: A prospective cohort study. Brain 128, 2556-2561.

[93] Teasdale GM, Nicoll JAR, Murray G, Fiddes M (1997) Association of apolipoprotein E polymorphism with outcome after head injury. Lancet 350, 1069-1071.

[94] Chamelian L, Reis M, Feinstein A (2004) Six-month recovery from mild to moderate traumatic brain injury: The role of APOE-E4 allele. Brain 127, 2621-2628.

[95] Blackman JA, Worley G, Strittmatter WJ (2005) Apolipoprotein E and brain injury: Implications for children. Dev Med Child Neurol 47, 64-70.

[96] Yassine HN, Croteau E, Rawat V, Hibbeln JR, Rapoport SI, Cunnane SC and Umhau JC (2017) DHA brain uptake and APOE4 status: A PET study with $\left[1-{ }^{11} \mathrm{C}\right]-\mathrm{DHA}$. Alzheimers Res Ther $\mathbf{9}, 23$.

[97] Tambini MD, Pera M, Kanter E, Yang H, GuardiaLaguarta C, Holtzman D, Sulzer D, Area-Gomez E, Schon EA (2016) APOE4 upregulates the activity of mitochondria-associated ER membranes. EMBO Rep 17, 27-36.

[98] Dose J, Huebbe P, Nebel A, Rimbach G (2016) APOE genotype and stress response - a mini review. Lipids Health Dis 15, 121.

[99] Ramassamy C, Averill D, Beffert U, Theroux L, LussierCacan S, Cohn JS, Christen Y, Schoofs A, Davignon J, Poirier J (2000) Oxidative insults are associated with apolipoprotein E genotype in Alzheimer's disease brain. Neurobiol Dis 7, 23-37.

[100] Huebbe P, Nebel A, Siegert S, Moehring J, BoeschSaadatmandi C, Most E, Pallauf J, Egert S, Müller MJ, Schreiber S, Nöthlings U, Rimbach G (2011) APOE E4 is associated with higher vitamin D levels in targeted replacement mice and humans. FASEB J 25, 3262-3270.

[101] Ringman JM, Elashoff D, Geschwind DH, Welsh BT, Gylys KH, Lee C, Cummings JL, Cole GM (2012) Plasma signaling proteins in persons at genetic risk for Alzheimer disease: Influence of APOE genotype. Arch Neurol 69, 757-764.

[102] Stening E, Persson J, Eriksson E, Wahlund LO, Zetterberg H (2017) Specific patterns of whole-brain structural covariance of the anterior and posterior hippocampus in young APOE E4 carriers. Behav Brain Res 326, 256-264.

[103] Dowell NG, Evans SL, Tofts PS, King SL, Tabet N, Rusted JM (2016) Structural and resting-state MRI detects regional brain differences in young and mid-age healthy APOE-E4 carriers. NMR Biomed 29, 614-624.

[104] Dowell NG, Ruest T, Evans SL, King SL, Tabet N, Tofts PS, Rusted JM (2013) MRI of carriers of the apolipoprotein E E4 allele-evidence for structural differences in normal-appearing brain tissue in E4+ relative to E4-young adults. NMR Biomed 26, 674-682.

[105] Alexopoulos P, Schmidinger TR, Horn M, Maus S, Reichel M, Sidiropoulos C, Rhein C, Lewczuk P, Doerfler A, Kornhuber J (2011) Hippocampal volume differences between healthy young apolipoprotein E E2 and E4 carriers. $J$ Alzheimers Dis 26, 207-210.

[106] Sidiropoulos C, Jafari-Khouzani K, Soltanian-Zadeh H, Mitsias P, Alexopoulos P, Richter-Schmidinger T, Reichel M, Lewczuk P, Doerfler A, Kornhuber J (2011) Influence of brain-derived neurotrophic factor and apolipoprotein E genetic variants on hemispheric and lateral ventricular volume of young healthy adults. Acta Neuropsychiatr 23, 132-138.

[107] Filippini N, MacIntosh BJ, Hough MG, Goodwin GM, Frisoni GB, Smith SM, Matthews PM, Beckmann CF, Mackay CE (2009) Distinct patterns of brain activity in young carriers of the APOE-E4 allele. Proc Natl Acad Sci U S A 106, 7209-7214.

[108] Scarmeas N, Habeck CG, Hilton J, Anderson KE, Flynn J, Park A, Stern Y (2005) APOE related alterations in cerebral activation even at college age. J Neurol Neurosurg Psychiatry 76, 1440-1444.

[109] Reiman EM, Chen K, Alexander GE, Caselli RJ, Bandy D, Osborne D, Saunders AM, Hardy J (2004) Functional brain abnormalities in young adults at genetic risk for lateonset Alzheimer's dementia. Proc Natl Acad Sci U SA 101, 284-289.

[110] Evans S, Dowell NG, Tabet N, King SL, Hutton SB, Rusted JM (2017) Disrupted neural activity patterns to novelty and effort in young adult APOE-E4 carriers performing a subsequent memory task. Brain Behav 7, e00612.

[111] Dennis NA, Browndyke JN, Stokes J, Need A, Burke JR, Welsh-Bohmer KA, Cabeza R (2010) Temporal lobe functional activity and connectivity in young adult APOE E4 carriers. Alzheimers Dement 6, 303-311.

[112] Turic D, Fisher PJ, Plomin R, Owen MJ (2001) No association between apolipoprotein E polymorphisms and general cognitive ability in children. Neurosci Lett 299, 97-100.

[113] Luciano M, Gow AJ, Harris SE, Hayward C, Allerhand M, Starr JM, Visscher PM, Deary IJ (2009) Cognitive ability at age 11 and 70 years, information processing speed, and 
APOE variation: The Lothian Birth Cohort 1936 Study. Psychol Aging 24, 129-138.

[114] Ruiz JR, Castillo R, Labayen I, Moreno LA, Fuentes MG, Lamuño DG, Alvarez Granda JL, Lucia A, Ortega FB (2010) Individual and combined effects of APOE and MTHFR $677 \mathrm{C} / \mathrm{T}$ polymorphisms on cognitive performance in Spanish adolescents: The AVENA Study. $J$ Pediatr 156, 978-984.

[115] Bunce D, Anstey KJ, Burns R, Christensen H, Easteal S (2011) Does possession of apolipoprotein E $\varepsilon 4$ benefit cognitive function in healthy young adults? Neuropsychologia 49, 1693-1697.

[116] Richter-Schmidinger T1, Alexopoulos P, Horn M, Maus S, Reichel M, Rhein C, Lewczuk P, Sidiropoulos C, Kneib T, Perneczky R, Doerfler A, Kornhuber J (2011) Influence of brain-derived neurotrophic-factor and apolipoprotein $\mathrm{E}$ genetic variants on hippocampal volume and memory performance in healthy young adults. J Neural Transm 118, 249-257.

[117] Yasen AL, Raber J, Miller JK, Piper BJ (2015) Sex, but not apolipoprotein E polymorphism, differences in spatial performances in young adults. Arch Sex Behav 44, 22192226.

[118] Bloss CS, Delis DC, Salmon DP, Bondi MW (2010) APOE genotype is associated with left-handedness and visuospatial skills in children. Neurobiol Aging 31, 787-795.

[119] Stening E, Persson J, Eriksson E, Wahlund LO, Zetterberg $\mathrm{H}$, Soderland H (2016) Apolipoprotein E E4 is positively related to spatial performance but unrelated to hippocampal volume in healthy young adults. Behav Brain Res 299, 11-18.

[120] Trumble BC, Stieglitz J, Blackwell AD, Allayee H, Beheim B, Finch CE, Gurven M, Kaplan H (2018) Apolipoprotein E4 is associated with improved cognitive function in Amazonian forager-horticulturists with a high parasite burden. FASEB J 31, 1508-1515.

[121] Sinclair LI, Button KS, Munafo MR, Day INM, Lewis G (2015) Possible association of APOE genotype with working memory in young adults. PLoS One 10, e0135894.

[122] Oria RB, Patrick PD, Zhang H, Lorntz B, de Castro Costa CM, Brito GA, Barrett LJ, Lima AA, Guerrant RL (2005) APOE4 protects the cognitive development in children with heavy diarrhea burdens in northeast Brazil. Pediatr Res 57, 310-316.

[123] Oria RB, Patrick PD, Blackman JA, Lima AA, Guerrant RL (2007) Role of apolipoprotein E4 in protecting children against early childhood diarrhea outcomes and implications for later development. Med Hypotheses $\mathbf{6 8}$, 1099-1107.

[124] Oria RB, Patrick PD, Oria MO, Lorntz B, Thompson MR, Azevedo OG, Lobo RN, Pinkerton RF, Guerrant RL, Lima AA (2010) APOE polymorphisms and diarrheal outcomes in Brazilian shanty town children. Braz J Med Biol Res 43, 249-256.

[125] Puttonen S, Elovainio M, Kivimaki M, Lehtimaki T, Jarvinen LK (2003) The combined effects of apolipoprotein E polymorphism and low-density lipoprotein cholesterol on cognitive performance in young adults. Neuropsychobiology $48,35-40$.

[126] Taylor AE, Guthrie PAI, Smith GD, Golding J, Sattar N, Hingorani AD, Deanfield JE, Day IN (2011) IQ, educational attainment, memory and plasma lipids: Associations with apolipoprotein E genotype in 5995 children. Biol Psychiatry 70, 152-158.
[127] Yu YWY, Lin CH, Chen SP, Hong CJ, Tsai SJ (2000) Intelligence and event-related potentials for young female human volunteer apolipoprotein E E4 and non-E4 carriers. Neurosci Lett 294, 179-181.

[128] Tsai SJ, Yu YWY, Hong CJ (2004) Personality traits in young female apolipoprotein E (APOE) E4 and non-E4 carriers. Am J Med Genet B Neuropsychiatr Genet 124B, 58-60.

[129] Jarvinen LK, Raikkonen K, Lehtimaki T (1993) Dependence between apolipoprotein $\mathrm{E}$ phenotypes and temperament in children, adolescents, and young adults. Psychosom Med 55, 155-163.

[130] Rusted JM, Evans SL, King SL, Dowell N, Tabet N, Tofts PS (2013) APOE E4 polymorphism in young adults is associated with improved attention and indexed by distinct neural signatures. Neuroimage 65, 364-373.

[131] Mondadori CR, de Quervain DJ, Buchmann A, Mustovic H, Wollmer MA, Schmidt CF, Boesiger P, Hock C, Nitsch RM, Papassotiropoulos A, Henke K (2007) Better memory and neural efficiency in young apolipoprotein E E4 carriers. Cereb Cortex 17, 1934-1947.

[132] Acevedo SF, Piper BJ, Craytor MJ, Benice TS, Raber J (2010) Apolipoprotein E4 and sex affect neurobehavioral performance in primary school children. Pediatr Res 67, 293-299.

[133] Noe E, Ferri J, Colomer C, Moliner B, Chirivella J (2010) APOE genotype and verbal memory recovery during and after emergence from post-traumatic amnesia. Brain Injury 24, 886-892.

[134] Chang L, Andres M, Sadino J, Jiang CS, Nakama H, Miller E, Ernst T (2011) Impact of apolipoprotein E E4 and HIV on cognition and brain atrophy: Antagonistic pleiotropy and premature brain aging. Neuroimage 58, 1017-1027.

[135] Jochemsen HM, Muller M, van der Graaf Y, Geerlings MI (2012) APOE E4 differentially influences change in memory performance depending on age. The SMART-MR study. Neurobiol Aging 33, 832e15-832e22.

[136] Zokaei N, Giehl K, Sillence A, Neville MJ, Karpe F, Nobre AC, Husain M (2017) Sex and APOE: A memory advantage in male APOE E4 carriers in midlife. Cortex $\mathbf{8 8 ,}$ 98-105.

[137] Alexander DM, Williams LM, Gatt JM, Dobson-Stone C, Kuan SA, Todd EG, Schofield PR, Cooper NJ, Gordon E (2007) The contribution of apolipoprotein E alleles on cognitive performance and dynamic neural activity over six decades. Biol Psychol 75, 229-238.

[138] Wright RO, Hu H, Silverman EK, Tsaih SW, Schwartz J, Bellinger D, Palazuelos E, Weiss ST, Hernandez-Avila M (2003) Apolipoprotein E genotype predicts 24-month Bayley Scales Infant Development Score. Pediatr Res 54, 819-825.

[139] Hubacek JA, Pitha J, Skodova Z, Adamkova V, Lanska V, Poledne R (2001) A possible role of apolipoprotein E polymorphism in predisposition to higher education. Neuropsychobiology 43, 200-203.

[140] Marchant NL, King SL, Tabet N, Rusted JM (2010) Positive effects of cholinergic stimulation favor young APOE E4 carriers. Neuropsychopharmacology 35, 1090-1096.

[141] Mitter SS, Oria RB, Kvalsund MP, Pamplona P, Joventino ES, Mota RM, Gonçalves DC, Patrick PD, Guerrant RL, Lima AA (2012) Apolipoprotein E4 influences growth and cognitive responses to micronutrient supplementation in shantytown children from northeast Brazil. Clinics 67, 11-18. 
[142] Caselli RJ, Dueck AC, Osborne D, Sabbagh MN, Connor DJ, Ahern GL (2009) Longitudinal modeling of agerelated memory decline and the APOE $\varepsilon 4$ effect. $N$ Engl $J$ Med 361, 255-263.

[143] Lancaster C, Tabet N, Rusted J (2017) The elusive nature of APOE $\varepsilon 4$ in mid-adulthood: Understanding the cognitive profile. J Int Neuropsychol Soc 23, 239-253.

[144] Sinclair LI, Pleydell-Pearce CW, Day INM (2017) Possible positive effect of the APOE $\varepsilon 2$ allele on cognition in early to mid-adult life. Neurobiol Learn Mem 146, 37-46.

[145] Tuminello ER, Han SD (2011) The apolipoprotein E antagonistic pleiotropy hypothesis: Review and recommendations. Int J Alzheimers Dis 2011, 726197.

[146] Fullerton SM, Clark AG, Weiss KM, Nickerson DA, Taylor SL, Stengârd JH, Salomaa V, Vartiainen E, Perola M, Boerwinkle E, Sing CF (2000) Apolipoprotein E variation at the sequence haplotype level: Implications for the origin and maintenance of a major human polymorphism. Am J Hum Genet 67, 881-900.

[147] Farrer LA, Cupples LA, Haines JL, Hyman B, Kukull WA, Mayeux R, Myers RH, Pericak-Vance MA, Risch N, van Duijn CM (1997) Effects of age, sex, and ethnicity on the association between apolipoprotein E genotype and Alzheimer disease: A meta-analysis. JAMA 278, 13491356.

[148] Suri S, Mackay CE, Kelly ME, Germuska M, Tunbridge EM, Frisoni GB, Matthews PM, Ebmeier KP, Bulte DP, Filippini N (2015) Reduced cerebrovascular reactivity in young adults carrying the APOE E4 allele. Alzheimers Dement 11, 648-657.

[149] Leon AS, Togashi K, Rankinen T, Després JP, Rao DC, Skinner JS, Wilmore JH, Bouchard C (2004) Association of apolipoprotein $\mathrm{E}$ polymorphism with blood lipids and maximal oxygen uptake in the sedentary state and after exercise training in the HERITAGE Family Study. Metabolism 53, 108-116.
[150] Coto-Segura P, Coto E, Alvarez V, Morales B, Soto-Sánchez J, Corao AI, Santos-Juanes J (2010) Apolipoprotein E4 allele is associated with psoriasis severity. Arch Dermatol Res 302, 145-149.

[151] Gozal D, Capdevila OS, Gozal LK, McLaughlin V (2007) APOE E4 allele, cognitive dysfunction, and obstructive sleep apnea in children. Neurology 69, 243-249.

[152] Wozniak MA, Riley EM, Itzhaki RF (2004) Apolipoprotein E polymorphisms and risk of malaria. J Med Genet 41, 145-146.

[153] Perkins M, Wolf AB, Chavira B, Shonebarger D, Meckel JP, Leung L, Ballina L, Ly S, Saini A, Jones TB, Vallejo J, Jentarra G, Valla J (2016) Altered energy metabolism pathways in the posterior cingulate in young adult apolipoprotein E $\varepsilon 4$ carriers. J Alzheimers Dis $\mathbf{5 8}$, 95-106.

[154] Pomara N, Belzer KD, Silva R, Cooper TB, Sidtis JJ (2008) The apolipoprotein E E4 allele and memory performance in HIV-1 seropositive subjects: Differences at baseline but not after acute oral lorazepam challenge. Psychopharmacology 201, 125-135.

[155] Wishart HA, Saykin AJ, Rabin LA, Santulli RB, Flashman LA, Guerin SJ, Mamourian AC, Belloni DR, Rhodes $\mathrm{CH}, \mathrm{McAllister}$ TW (2006) Increased brain activation during working memory in cognitively intact adults with the APOE E4 allele. Am J Psychiatry 163, 1603-1610.

[156] Nijenhuis JT, Choi KY, Choi YY, Lee JJ, Seo EH, Kim H, Lee KH (2018) Differences between APOE carriers and non-APOE carriers on neurocognitive tests: Jensen Effects? Am J Alzheimers Dis Other Demen 33, 353-361.

[157] Evans S, Gray MA, Dowell NG, Tabet N, Tofts PS, King SL, Rusted JM (2013) APOE E4 carriers show prospective memory enhancement under nicotine, and evidence for specialization within medial BA10. Neuropsychopharmacology 38, 655-663. 